Anderson Luiz Coan

Técnica de preços para determinação de mercado relevante e proposta de visualização de resultados 
Anderson Luiz Coan

\section{Técnica de preços para determinação de mercado relevante e proposta de visualização de resultados}

Dissertação apresentada à Escola de Artes, Ciências e Humanidades da Universidade de São Paulo para obtenção do título de Mestre em Ciências pelo Programa de Pós-graduação em Sistemas de Informação.

Versão corrigida contendo as alterações solicitadas pela comissão julgadora em 20 de fevereiro de 2014. A versão original encontrase em acervo reservado na Biblioteca da EACH-USP e na Biblioteca Digital de Teses e Dissertações da USP (BDTD), de acordo com a Resolução CoPGr 6018, de 13 de outubro de 2011.

Orientador: Prof. ${ }^{a}$ Dra ${ }^{a}$ Marislei Nishijima

São Paulo 
Autorizo a reprodução e divulgação total ou parcial deste trabalho, por qualquer meio convencional ou eletrônico, para fins de estudo e pesquisa, desde que citada a fonte.

\section{CATALOGAÇÃO-NA-PUBLICAÇÃO}

Biblioteca

Escola de Artes, Ciências e Humanidades da Universidade de São Paulo

\section{Coan, Anderson Luiz}

Técnica de preços para determinação de mercado relevante e proposta de visualização de resultados / Anderson Luiz Coan ; orientadora, Marislei Nishijima. - São Paulo, 2014.

$81 \mathrm{f.}:$ il.

Dissertação (Mestrado em Ciências) - Programa de PósGraduação em Sistemas de Informação, Escola de Artes, Ciências e Humanidades, Universidade de São Paulo.

Versão corrigida.

1. Preços - Economia. 2. Preços - Técnicas - Testes. 3. Análise multivariada. 4. Computação aplicada. 5. Mercado relevante. I. Nishijima, Marislei, orient. II. Título.

CDD 22.ed. -338.43 


\section{ATA DE DEFESA DE DISSERTAÇÃO}

A Comissão Julgadora da defesa de dissertação de mestrado reuniu-se na data de 20 de fevereiro de 2014, às 14h00, na Sala C1 do Laboratório de Arquitetura e Redes de Computadores, da Escola Politécnica da Universidade de São Paulo, São Paulo (SP), para arguir, em sessão pública, o(a) aluno(a) Anderson Luiz Coan, do Programa de Pós-Graduação em Sistemas de Informação (Mestrado), referente à dissertação intitulada "TÉCNICA DE PREÇOS PARA DETERMINAÇÃO DE MERCADO RELEVANTE E PROPOSTA DE VISUALIZAÇÃO DE RESULTADOS". A sessão iniciou-se com a apresentação da dissertação pelo(a) aluno(a) seguida de arguição pelos examinadores, que decidiram pela APROVACYÃO_ (aprovação/reprovação) do aluno na defesa de dissertação de mestrado, conforme avaliação dos examinadores a seguir.

Prof $^{a}$ Dr $^{a}$ Marislei Nishijima

Prof. Dr. Emerson Fernandes Marçal

Prof. Dr. Helton Hideraldo Bíscaro

\section{Resultado: APRoVADO}

Resultado: aprovado

Resultado:

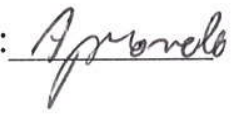

São Paulo, 20 de fevereiro de 2014.

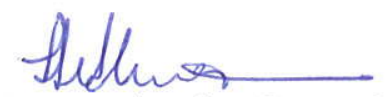

Prof $^{\mathrm{a}} \mathrm{Dr}^{\mathrm{a}}$ Fátima de Lourdes dos Santos Nunes Marques

Coordenadora de Programa

Sistemas de Informação

EACH-USP 
Dedico esse trabalho a minha noiva, Sonia Dias, que a todo o momento me incentivou arduamente para a conclusão dessa pesquisa. 
Agradeço a minha orientadora, prof. ${ }^{\text {a }}$ Dr. ${ }^{\text {a }}$ Marislei Nishijima pela dedicação, tempo e paciência em suas orientações para a realização desse trabalho. Também agradeço a prof. ${ }^{\text {a }}$ Dr. ${ }^{\text {a }}$ Fátima Nunes pelos ensinamentos compartilhados, ao prof. ${ }^{\circ}$ Dr. ${ }^{\circ}$ Helton Bíscaro pela paciência em compartilhar e oferecer sugestões e também um agradecimento especial aos meus colegas de sala David Pereira Barbosa, Renata Madeo, Jadson e Leila, que contribuíram muito com suas experiências e dedicações. 
"Ontem é passado. Amanhã futuro. Hoje, agora. Ontem foi. Amanhã será. Hoje é. Ontem, experiência adquirida. Amanhã, lutas novas. Hoje, porém, é a nossa hora de fazer e de construir."

(Trecho do poema do espírito Emmanuel, psicografado por Chico Xavier). 


\section{Resumo}

COAN, Anderson Luiz. Técnica de preços para determinação de mercado relevante e proposta de visualização de resultados. 2014. 81 f. Dissertação (Mestrado em Ciências) Escola de Artes, Ciências e Humanidades, Universidade de São Paulo, São Paulo, 2014.

O teste do monopolista hipotético, descrito nos guias de defesa da concorrência dos vários países do mundo, consiste na metodologia usada para definir o tamanho do mercado de um bem. Os testes de preços constituem uma das formas de operacionalizar o teste do monopolista hipotético via análise de cointegração. Considerando a ausência de intersecção desta área antitruste da economia com a área de computação, esse trabalho desenvolveu e implementou o teste de cointegração não linear de Kapetanios et al. (2006), como proposta de teste de preços, para avaliar se estes bens pertencem a um mesmo mercado relevante. Este objetivo é vinculado ao desenvolvimento de uma ferramenta visual de informação (computacional) com o objetivo de facilitar a apresentação vinculada aos resultados obtidos, uma vez que a área de antitruste envolve diferentes grupos de profissionais e agentes (consumidores e produtores). A ferramenta visual resultante busca facilitar a apresentação dos conceitos econômicos envolvidos em relação aos resultados normalmente apresentados.

Palavras Chave: Mercado relevante, técnica de preços, cointegração, visualização. 


\section{Abstract}

COAN, Anderson. Luiz. Price technique for relevant market determination and propose to view results. 2014. $81 \mathrm{f}$. Dissertation (Master of Science) - School of Arts, Sciences and Humanities, University of São Paulo, São Paulo, 2014.

The hypothetical monopolist test, described in guidebooks antitrust various countries of the world, is the methodology used to define the size of the market for a good. The tests of prices are one of the ways to operationalize the hypothetical monopolist test via cointegration analysis. Considering the absence of this intersection area of antitrust economics to the field of computing, this paper developed and implemented the nonlinear cointegration test of Kapetanios et al. (2006), as proposed price test to assess whether these goods belong to the same relevant market. This objective is linked to the development of a visual tool for information (computational) in order to facilitate the presentation linked to the results obtained, since the area of antitrust involves different groups of professionals and agents (consumers and producers). The resulting visual search tool facilitate the presentation of economic concepts involved in relation to the results presented normally.

Keywords: Relevant market, technical pricing, cointegration, visualization. 


\section{Lista de Figuras}

Figura 01 Exemplo de uma representação ScatterPlot

Figura 02 Andrews plot mostrando a mediana e $1^{\circ}$ quartilho de uma base de dados agrupada

Figura 03 Glyphplot mostrando os dados agrupados com desenho de estrela

Figura 04 Glyphplot mostrando os dados agrupados com desenho de face

Figura 05 Dados brutos agrupados

Figura 06 Plotando somente a mediana e os quartilhos de cada grupo

Figura 07 Tela gráfica do GUIDE

Figura 08 Modelo de visualização. Adaptado de (NASCIMENTO ET al., 2004 apud SOUZA, 2007)

Figura 09 Tela de bem vindo

Figura 10 Tela principal do programa

Figura 11 Janela de propriedades dos controles

Figura 12 Diagrama de blocos da aplicação

Figura 13 Primeiro passo: Abertura da base de dados

Figura 14 Seleção de variável única para teste de raiz unitária

Figura 15 Tela de demonstração dos resultados de raiz unitária

Figura 16 Aplicação do mecanismo de correção de erro

Figura $17 \quad$ Tela de coordenadas paralelas ............................................................ 59

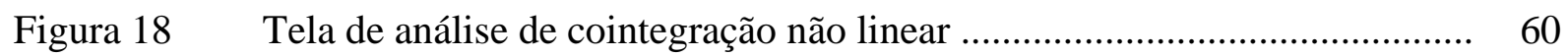

Figura 19 Tela do teste de cointegração com os gráficos de dados ajustados ............. 61

Figura $20 \quad$ Telas com os resultados de FNEC e F*NEC …........................................ 62

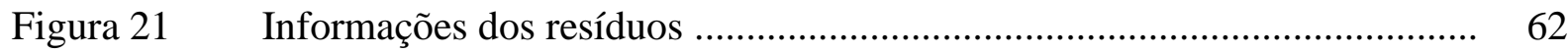




\section{Lista de Tabelas}

Tabela $01 \quad$ Valores comuns de cada variável........................................................ 14

Tabela 02 Trabalhos correlatos usados como referência ............................................ 40

Tabela 03 Comparativo de testes de raiz unitária em cada variável .......................... 57 


\section{Sumário}

TESTE DO MONOPOLISTA HIPOTÉTICO

2.1 Mercado relevante, teste do monopolista hipotético e testes de preços em análises antitrustes.

2.2 Teste de Preços - Definições de integração e cointegração $\quad$................................... 20

2.3 Modelo de Correção de Erros Linear e Não Linear $\quad$............................................. 22

2.4 Estratégia metodológica e teste para cointegração em modelos de correção de erro de transição suave não linear

CONTEXTUALIZAÇÃO TEÓRICA DE REPRESENTAÇÃO VISUAL........ 28

3.1 Técnicas de visualização: conceito geral...................................................... 28

3.2 Modelos de visualização de dados estatísticos multivariados................................ 30

3.3 Trabalhos Correlatos................................................................................ 38

3.4 Contribuições na área de visualização............................................................... 43

4 DESENVOLVIMENTO DA REPRESENTAÇÃO VISUAL ............................ 45

4.1 Visualização de informação (VI) construída através da ferramenta MatLab®......... 45

4.2 Desenvolvimento da visualização dos resultados por representação gráfica ........... 46

4.3 Desenvolvimento do sistema SITEMERE..................................................... 49

$5 \quad$ RESULTADOS



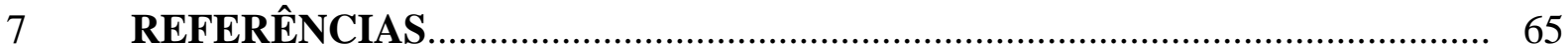

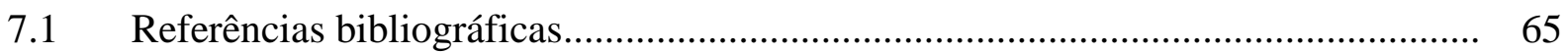

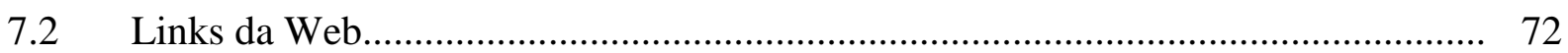


A Comandos de programação comentados......................................................... 73

ANEXOS






\section{Capítulo 1}

\section{Introdução}

Usualmente as técnicas para a determinação de mercado relevante são baseadas em análises de demanda e de suas respectivas elasticidades-preço. Entretanto, existe um conjunto de países, tais como o Reino Unido, Finlândia e Brasil, que aceitam adicionalmente os testes de preços como forma de determinar o mercado relevante. Os testes de preços, dada a natureza das séries de preços, são conduzidos por meio de análises de cointegração, que consistem na constatação da existência de uma relação estável de longo prazo entre duas ou mais séries de tempo de preços. Entre os procedimentos tomados para avaliação de cointegração o mais comumente empregado é o procedimento de Johansen(Johansen 1991 e 1995). Estes testes, no entanto, supõem linearidade ao mecanismo de correção de erros (ECM, do inglês Error Correction Mechanism), que corrige os desvios de curto prazo da tendência estocástica de longo prazo.

O teste do monopolista hipotético é a metodologia empregada para definir o mercado relevante, ou seja, o mercado de um bem $^{1}$ ou serviço. De acordo com esta metodologia o mercado relevante consiste no menor grupo de produtos e na menor área geográfica necessários para que um suposto monopolista esteja em condições de impor um 'pequeno, porém significativo e não transitório' aumento de preços, exercendo assim poder de mercado em favor de sua empresa (U.S. Merge Guide, 2010).

O objetivo do teste do monopolista hipotético é definir empiricamente o tamanho de um mercado, ou seja, determinar se um grupo de produtos pesquisados pertence a um mesmo mercado relevante quando avaliado em suas duas dimensões: a geográfica; e a de tipos de produtos/bens.

Esta delimitação permite mensurar/avaliar o grau de concentração em atos de fusões e aquisições e também a existência ou possibilidade da formação de cartel, configurando problemas de condutas/ações nos mercados específicos(Ministério da fazenda, 2001).

No Brasil é o Sistema Brasileiro de Defesa da Concorrência (SBDC), tendo o CADE (Conselho Administrativo de Defesa Econômica) a função de julgamento, quem deve orientar,

\footnotetext{
${ }^{1}$ Deve-se notar que em economia o conceito de bem engloba tantos produtos em geral como serviços.
} 
fiscalizar, prevenir, apurar abusos de poder econômico, exercendo um papel tutelar e de regulação. Do ponto de vista da regulação econômica, o aumento de preços decorrente do exercício de poder de mercado, com a finalidade de aumentar lucros, pode causar uma transferência de renda dos consumidores para os produtores e perdas significativas de bemestar para a sociedade(Ministério da fazenda, 2001;U.S. Department of Justice, 2010 e Salgado, 2011).

Para que análises desta natureza sejam conduzidas é preciso determinar o tamanho do mercado, isto é, o mercado relevante, em relação ao qual cada discussão é feita e avaliada.

Os guias de concentração horizontal dos sistemas de defesa da concorrência em diversos países, inclusive Brasil, definem o método do teste do monopolista hipotético como metodologia para a definição de mercado relevante $^{2}$. Porém, este método pode ser implementado de várias maneiras alternativas, em geral por meio de estimações de sistemas de demanda (uma demanda para cada bem do mercado) e análises com base em suas elasticidades-preço cruzadas e próprias relacionadas ou por testes de correlação de preços.

Deste modo, avaliar se ações ou acordos são anti-competitivos e se ocorrem abusos de posição dominante exige a aplicação do teste do monopolista hipotético que pode ser conduzida de várias maneiras alternativas. Para a sua execução por meio de estimativas de demanda, entretanto, são necessárias muitas informações sobre as empresas envolvidas e das demais empresas e de todos os consumidores. De modo que a falta de disponibilidade de informações, ou mais precisamente, o seu alto custo de obtenção (em recursos inclusive tempo) para as autoridades da defesa da concorrência limitam a sua capacidade de análise, bem como dos demais agentes envolvidos, tais como outras empresas, entidades representantes dos consumidores e etc.

A vantagem dos testes de preços para determinação do mercado relevante de um bem é o fato de utilizar reduzido número de informações comparado com a alternativa de estimação de sistemas de demanda. Exigindo informações apenas sobre preços negociados e algumas séries de preços de insumos relacionados, o que implica menor custo para a análise (Baker e Bresnahan 2006).

Deve-se notar que uma das características da área antitruste é ser interdisciplinar, uma vez que advogados, que são os representantes legais das partes envolvidas, e economistas, além de matemáticos e estatísticos, atuam de maneira conjunta na definição de casos. Sendo

\footnotetext{
${ }^{2}$ Merges and Aquisitions Guidelines, 2004; Ministério da fazenda, 2001.
} 
assim, verifica-se espaço aberto para o desenvolvimento de uma ferramenta visual para a apresentação dos resultados dos testes de preços conduzidos, que pode contribuir sobremaneira como um instrumento adicional para as análises desta natureza.

No contexto descrito acima, o objetivo deste trabalho é duplo. O primeiro é implementar o teste de cointegração de Kapetanios et al. (2006) como uma aplicação para testes de preços para determinação de mercado relevante. Trata-se de uma técnica de preços que permite não linearidades decorrentes de mudanças de regimes de processos geradores das séries de tempo conduzidas de maneira suavizada. Para uma aplicação são usados dados mensais de preços de medicamentos sob a hipótese de que o mercado geográfico relevante destes produtos é o Brasil, deve-se notar que num levantamento sobre os casos de medicamentos avaliados pelo CADE mostra que considerar o Brasil como mercado geográfico tem sido a regra geral. O segundo objetivo é desenvolver/implementar uma técnica de visualização computacional para a visualização dos resultados de mercado relevante para o público interessado a partir dos resultados dos testes de preços, que são conhecidos por sua reduzida exigência de quantidade de informações.

Para este estudo foram usados os preços de medicamentos da subclasse terapêutica M01A1, nível 4, da classe Human musculoskeletal system da classificação "The Anatomical Therapeutic Chemical (ATC) Classification System" usada para agrupar medicamentos por área de atuação no organismo pela organização mundial da Saúde (WHO). Abaixo, uma tabela com os valores padrões de cada variável:

\begin{tabular}{|c|l|l|l|l|l|l|l|}
\hline $\begin{array}{c}\text { Variáveis/ } \\
\text { Valores }\end{array}$ & Med2 & Med5 & Med6 & Med7 & Med8 & Med9 & Med11 \\
\hline Média & 8,84 & 10,30 & 10,94 & 14,56 & 4,97 & 7,50 & 7,16 \\
\hline Desvio padrão & 0,64 & 0,22 & 1,51 & 2,60 & 0,93 & 0,16 & 0,14 \\
\hline Valor máximo & 9,79 & 10,79 & 13,60 & 18,71 & 6,53 & 7,85 & 7,46 \\
\hline Valor Mínimo & 7,65 & 9,51 & 8,90 & 10,03 & 3,47 & 7,06 & 6,83 \\
\hline
\end{tabular}

Tabela 01 - Valores comuns de cada variável

Considerando o caráter interdisciplinar da área antitruste e o tipo de trabalho técnico que envolve, a contribuição da área de Sistemas de Informação pode ser bastante significativa. Isso porque tanto a delimitação do mercado relevante quanto sua apresentação para os agentes 
envolvidos tem por natureza/requerem técnicas de computação alinhadas aos sistemas de informação envolvidos, ainda que exista pequena interação entre estas áreas, técnicas de preços aplicadas à determinação de mercados relevantes, uma subárea da economia, e a área de computação, conforme será visto com a apresentação dos resultados da revisão sistemática realizada para esta finalidade.

Os diferentes métodos para a viabilização do teste do monopolista hipotético são extremamente demandantes de insumos computacionais. Assim, conhecer o estado das artes na delimitação de mercados relevantes de produtos, neste caso as técnicas de preços, e avaliar sua interação com técnicas computacionais e sistemas de informação, permite realizar uma contribuição direcionada e inserida nesta interseção de áreas de conhecimento.

Além disso, contribuir com uma ferramenta visual didática impõe uma inovação como possibilidade de uso, oferecendo uma possibilidade ainda não disponível aos agentes envolvidos em análises antitrustes.

Para fundamentar nossa proposta e conhecer o grau de intersecção entre as áreas mencionadas, um trabalho de Revisão Sistemática (RS) foi realizado no período entre novembro de 2011 e fevereiro de 2012, conforme Coan et al. (2013). A RS, Kitchenham (2004) e Biolchini et al. (2005), buscou verificar o grau de sobreposição entre testes de preços para a determinação do Mercado relevante na área de economia e na área de computação/ sistemas de informação e foi conduzida em duas rodadas. A segunda rodada teve a finalidade de confirmar os resultados obtidos na primeira rodada no que se refere o uso de técnicas similares nas duas áreas pesquisadas. Especificamente, investigou o uso de técnicas de cointegração (método de Engle-Granger, Buriens e Johansen) em aplicações de computação/ sistemas de informação. Já a primeira rodada ficou concentrada na busca da relação de assuntos de economia direcionados a técnicas de determinação de mercado relevante por série de preços.

Os resultados da RS mostraram pequeno grau de sobreposição entre a subárea de economia em mercado relevante e técnicas computacionais. A intersecção se restringe ao uso de técnicas estatísticas (testes de cointegração) linear e não linear que se relacionam com implementações computacionais para soluções numéricas de parâmetros estimados. Em particular não se encontrou aplicações da técnica de preços não lineares de Kapetanios et al. (2006) nestas buscas, o que mostra a potencial contribuição do estudo aqui proposto. 
A intersecção existe apenas em aplicações específicas de economia, outras que não há determinação de mercados relevantes, tais como em preços de ações em mercados financeiros. Os resultados da intersecção entre técnicas de cointegração linear e não linear, sugerem um campo aberto de pesquisa interdisciplinar entre as áreas de economia e sistemas de informação com várias possibilidades de desenvolvimento, entre elas o emprego de técnicas de preços em mercados relevantes e a possibilidade do uso de instrumento visual como auxílio destas aplicações.

Como uma das características da área antitruste é ser interdisciplinar, verificou-se a possibilidade de propor um método para interpretar os resultados de testes de preços, através da visualização da informação, por meio de representações gráficas, que se mostrou uma solução bastante atraente dado o desenvolvimento crescente de aplicações visuais. No tocante a visualização da informação, o recurso "Guide", que faz parte da aplicação $\operatorname{MatLab}{ }^{\circledR}$, se transformou no principal aliado para a construção dos resultados gráficos para posterior interpretação dos usuários interessados. Como será descrito no capítulo 03, a visualização possui vários enfoques distintos: a científica, a de informações, a estatística, a de processos, a de software, entre outras. A VI (Visualização da informação) implementada busca propiciar recursos para interpretar grandes volumes de dados armazenados de maneira sintética, sendo possível ser aplicada em diversas áreas do conhecimento, no nosso caso específico, na subárea de economia de análise de mercado relevante. Os dados analisados geralmente são séries de preços longas e a VI proposta é geral para qualquer tipo de série de tempo, independente da periodicidade, conforme instrumento construído em MatLab®. A VI procura reunir o poder de percepção visual humana com o poder do processamento do computador moderno possibilitando assim uma análise e compreensão do alto volume de dados de uma maneira rápida.

Além desta introdução, o trabalho está dividido em mais 5 capítulos. O capítulo 2 apresenta a fundamentação teórica para os testes do monopolista hipotético, principalmente a proposta de Kapetanios que trata a análise de cointegração não linear por transição suave. $\mathrm{O}$ capítulo 3 apresenta a fundamentação teórica para a visualização das informações, desde seus conceitos iniciais até suas justificativas para a implementação voltada para a área de análise de mercado e testes de cointegração. O capítulo 4 apresenta as etapas para a construção da representação visual. Os resultados econométricos obtidos para testes de raiz unitária, mecanismo de correção de erro, além da implementação dos cálculos de cointegração não linear proposto por Kapetanios (2006) está descrito no capítulo 5. Já o capítulo 6 apresenta as 
considerações finais e por fim, o capítulo 7, apresenta as referências bibliográficas consultadas para a realização desse trabalho. 


\section{Capítulo 2}

\section{Contextualização teórica: Testes de Preços como Teste do Monopolista Hipotético}

Nesta seção são abordados os conceitos fundamentais, relacionados à definição de mercados relevantes, necessários para compreensão do trabalho proposto. O conceito de testes de preços em relação ao qual será feita uma implementação se relaciona a um tipo de aplicação do teste do Monopolista Hipotético que só é aceito em algumas jurisdições, entre elas o Brasil. Nestas jurisdições a possibilidade de substituição entre bens, o que determina um mesmo mercado, pode ocorrer tanto pelo lado da demanda como pelo lado da oferta. No último caso tem-se a caracterização do conceito de "flexibilidade de oferta". A substituição pelo lado da oferta permite que dois produtos estejam no mesmo mercado relevante desde que um produtor possa arbitrar na produção de dois bens por meio de usos alternativos de seus insumos produtivos.

\subsection{Mercado relevante, teste do monopolista hipotético e testes de preços em análises antitrustes}

De acordo com o Guia brasileiro de concentração horizontal (Ministério da Fazenda, 2001) define-se mercado relevante como um conjunto de agentes econômicos, consumidores e produtores, que efetivamente limitam as decisões referentes a preços e quantidades da empresa resultante da operação. É determinado em termos de produtos e/ou serviços e da área geográfica para qual a venda destes produtos é economicamente viável. Um menor grupo de produtos e uma menor área geográfica são suficientemente necessários para que um suposto monopolista esteja em condições de impor um 'pequeno porém significativo e não transitório' aumento de preços. Esta definição, a do Monopolista Hipotético, é a mesma na maioria das jurisdições como é o caso dos Estados Unidos que são pioneiros na legislação antitruste (U.S. Merge Guide, 2010), conforme o U.S. Department of Justice (2010) e o Britain's Office of Fair Trading (OFT) (Salgado 2011). 
A ação de um suposto monopolista se torna mais evidente quando os consumidores não podem desviar uma parcela significativa da demanda para bens substitutos ou bens provenientes de outras regiões. O aumento do preço para o monopolista depende da reação dos consumidores que, por sua vez, é dada em função da propensão com que os consumidores estejam dispostos a desviar sua demanda para um produto substituto ou para um produto idêntico oriundo de outra área, como resposta a esse aumento(Ministério da Fazenda, 2001). O teste do monopolista hipotético é o instrumental analítico para se aferir o grau de substituição entre bens e serviços e determinar a amplitude de um mercado na prática.

De modo geral, existem duas linhas de testes para a determinação do mercado relevante, uma que se baseia em testes de elasticidades-preço da função demanda (sistema de demanda) resumida em Baker e Bresnahan (2008) e outra, mais recentemente adotada, baseada em testes de preços em acordo com Forni (2004). A primeira abordagem não é tratada neste estudo, para aplicações desta abordagem ao caso brasileiro ver Pinheiro e Pioner (2005). A segunda consiste em análises de séries de tempo de preços que em geral aplica análises de interação e de cointegração lineares, conforme será visto na sequência e na qual se propõe uma análise cointegração não linear para uma aplicação do mercado de medicamentos neste estudo.

Os testes de preços como forma de operacionalizar o teste do monopolista hipotético em análises antitruste não são aceitos em todas as jurisdições, por exemplo, os Estados Unidos não aceitam tais testes. Apenas em jurisdições que aceitam implicitamente também a substituição entre produtos pelo lado da oferta, caso do Brasil e da Europa em geral, quando existe flexibilidade na produção de modo que um produtor possa alocar diferentes quantidades dos mesmos insumos para produzir diferentes bens. Isso porque ao trabalhar com preços de equilíbrio como fonte de informação, parte-se de que movimentos podem ter ocorrido por substituição na oferta, ou seja, quando o produtor multiproduto deixa de usar seus insumos para produzir um bem e produz mais do outro porque os preços relativos são mais favoráveis a este último. A sua grande vantagem das técnicas de preços em termos de execução é o reduzido número de informações exigidas quando comparadas com estimativas de demanda tradicionais(Werden e Froeb 1993).

Os testes de preços são indicados para casos com disponibilidade de séries de tempo longas, pelo menos 5 anos de informações (não existe um prazo teórico ótimo, existe prática adotada), pois a metodologia de cointegração se aplica a longo prazo, e envolvem testes de integração e cointegração se séries de tempo de preços (Hendry 1995). 


\subsection{Teste de Preços - Definições de integração e cointegração}

Os testes de preços envolvem um conjunto de técnicas de análise de integração e de cointegração para o caso de séries de preços não estacionárias, pois na maioria dos casos as séries de preços nominais são não estacionárias, ou seja, são integradas. Para o caso de séries estacionárias os resultados das estatísticas tradicionais são válidos sem a necessidade de estudos de cointegração (Margarido 1999).

A média e a variância podem depender de um intervalo de tempo, só não pode depender de tempo unicamente. Isso porque o intervalo de tempo é finito e o tempo não. Se $y t$ vai a infinito, então a variância e a média explodem. O que não ocorre para intervalos. É dito variância para o conceito geral que engloba variância e covariância. No processo estacionário, a covariância, que é uma parte da variância, depende do intervalo de tempo.

Ou seja, para a estacionariedade a média não depende do tempo, a variância também não depende do tempo e a covariância depende apenas dos intervalos.

O conceito de cointegração é uma generalização dos processos integrados univariados em um contexto multivariado. Trata-se da possibilidade de existência de relações lineares ou não lineares estáveis, como o método a ser utilizado neste estudo, entre variáveis no longo prazo. Que isoladamente possuem ordem de integração n, mas quando em conjunto possuem ordem de integração menor do que a das variáveis presentes nesta relação linear, geralmente ordem de integração n-1. Pereira (1991) observa que o caso mais frequentemente estudado de co-integração é aquele que resulta em relações integradas estacionárias, I(0), uma vez que, neste caso, os resultados das análises com regressões lineares múltiplas são válidos.

O método clássico de estimação por regressão pressupõe que a média e a variância de uma série de tempo sejam constantes e independentes no tempo, ou seja, estacionárias. Contudo, se as séries forem não-estacionárias, de acordo com Margarido (1999) a maioria das séries de preços reais (preços nominais deflacionados) são I(1). Variáveis cujas médias e variâncias mudam ao longo do temposão conhecidas como não estacionárias ou variáveis (séries de tempo) com raiz unitária.

De acordo com Enders (2010), um Vetor Auto-Regressivo (VAR) de $n$ variáveis e de ordem $p, \boldsymbol{y}_{\boldsymbol{t}}=\boldsymbol{B}_{\mathbf{1}} \boldsymbol{y}_{t-\mathbf{1}}+\cdots+\boldsymbol{B}_{t-p} \boldsymbol{y}_{t-\boldsymbol{p}}+\boldsymbol{\varepsilon}_{\boldsymbol{t}}$, o último termo é um vetor de variáveis ruídos 
brancos, pode ser reescrito como um Vetor do Modelo de Correção de Erros (VEC) de ordem $q=p-1$, ou seja, $\boldsymbol{\Delta} \boldsymbol{y}_{\boldsymbol{t}}=\boldsymbol{C} \boldsymbol{y}_{\boldsymbol{t}-\mathbf{1}}+\sum_{i}^{q} \boldsymbol{B}^{\prime}{ }_{\boldsymbol{i}} \boldsymbol{y}_{\boldsymbol{t}-\boldsymbol{i}}+\boldsymbol{\varepsilon}_{\boldsymbol{t}}$. Esta última representação de processos cointegrados se deve a Granger e pode ser interpretado pelo fato dos agentes econômicos utilizarem "servomecanismos" que corrigem os erros cometidos previamente conforme uma relação de equilíbrio pré-estabelecida (Pereira 1991). A matriz $\boldsymbol{C}$ pode ser decomposta em suas matrizes de autovalores e de autovetores de modo que permite avaliar empiricamente se as séries de tempo contidas em $\boldsymbol{y}_{\boldsymbol{t}}$ cointegram ou não, sob a hipótese de serem integradas de ordem I(1) isoladamente. Assim, quando duas ou mais variáveis são cointegradas, isto implica na existência de uma relação estável (equilíbrio) de longo prazo entre elas. Embora a literatura de cointegração usando o método de Johansen, que permite a generalização para mais de um equilíbrio estável tem dominado as aplicações de cointegração linear (Forni 2003), focaremos o método de Engle e Granger uma vez que o modelo de cointegração não linear de Kapetanios et al. (2006) se baseia neste último método.

Na literatura antitruste, Haldrup (2003) e Forni (2004) argumentam que se duas séries de preços cointegram então os dois bens em questão pertencem ao mesmo mercado relevante. Isso porque se dois bens estão no mesmo mercado relevante os preços destes bens devem manter uma relação estável de longo prazo pela relação de substituição entre eles. À medida que o preço de um deles muda isso em período posterior tem impacto sobre o preço do outro bem quando a demanda se desloca em direção a tal bem.

Coe e Krause (2008) mostram que na ausência de choques os testes de cointegração podem ser usados para determinar mercado relevante. Este resultado é importante à medida que sinaliza que o uso da técnica de cointegração não linear, quando séries de preços sofrem choques, fenômeno frequente, ocasionando mudanças de regime, podem ser avaliadas por cointegração não linear, em acordo com a proposta deste estudo.

Kapetanios et al. (2006) propõem um novo procedimento de teste para detectar a presença de uma relação de cointegração não linear que segue um processo de transição suave globalmente estacionária tendo como base a metodologia do modelo de correção de erros de Engle e Granger (1987).No contexto de modelo de correção de erro não lineares por transição suave (ECMs) é proposto baseado em duas versões de testes operacionais. Em primeiro lugar, obtêm-se os associados não lineares baseados em testes de ECM (modelo de correção de erros); segundo, deriva-se a analogia não linear do teste residual baseada em cointegração em modelos lineares. Obtêm-se, então, as distribuições assintóticas dos testes propostos. Exercícios de simulações de Monte Carlo confirmam que a proposta de testes tem poder 
melhor do que as contrapartes lineares que apresentam alternativas de processo não-linear de cointegração globalmente estacionária.

Deve-se notar que este estudo se limita a estudar a relação de cointegração não linear sob a hipótese de que as séries de preços são I(1), testada por testes tradicionais de raiz unitária linear. Veja anexo 1 para testes de raiz unitária de DickeyFuller Aumentado e Phillips-Perron.

Houve também uma preocupação crescente de que a informação revelada pela análise de um modelo linear de séries temporais possa ser insuficiente para dar inferência definitiva sobre importantes hipóteses econômicas. A atenção a esse respeito caiu quase que exclusivamente em regime de comutação de tipos de modelos, embora não haja nenhuma teoria estabelecida que sugira uma abordagem única para a especificação de modelos econométricos que incorporam vários tipos de mudança de regimes. Estimativa de modelos cointegrados sujeito a (regime comutação) não linear dinâmica tem sido bastante proeminente. (Kapetanios 2006).

No trabalho de Kapetanios (2006) são considerados modelos de correção de erros por comutação de Markov (ECMs), em que os desvios do equilíbrio de longo prazo seguem um processo que é não-estacionário em um estado de natureza e de reversão de média no outro. De acordo com os autores, alguns estudos apontam o pequeno número de estudos especificando diretamente as derivações de propriedades assintóticas de teste de cointegração contra as alternativas não-lineares. Alguns realizam análise de cointegração com alternativas não-lineares em mente, adotando testes de cointegração linear para estabelecer a existência de cointegração e só permitir que entre na análise a não-linearidade, uma vez a cointegração foi estabelecida.

A investigação da não estacionariedade em conjunto com a modelagem não linear auto regressivo recentemente assumiu um papel de destaque no estudo econométrico. Esta tendência foi verificada pela Revisão Sistemática conduzida neste estudo para avaliar o grau de interação entre as áreas de conhecimento investigadas.

\subsection{Modelo de Correção de Erros Linear e Não Linear}

Um n-vetor $\boldsymbol{y}_{\mathrm{t}}$ é cointegrado se alguma combinação linear $\beta_{1} y_{1 t}+\cdots+\beta_{n} y_{n t}$ das variáveis que o compõem é estacionária descrevendo a relação de cointegração, sendo $\boldsymbol{\beta}=$ $\left(\beta_{1}, \ldots \beta_{n}\right)^{\prime}$ o vetor de cointegração. 
Se $\boldsymbol{y}_{\mathrm{t}}$ é um vetor n-dimensional e $\boldsymbol{\beta}$ é um vetor de cointegração, então $\boldsymbol{\beta}^{\prime} \boldsymbol{y}_{\boldsymbol{t}-\mathbf{1}}$ é uma medida de "erro" dos desvios dos dados em relação à média estacionária em t-1. O vetor $\boldsymbol{\alpha}$ mede a velocidade de ajustamento, que é incorporada no modelo VAR (vetor auto regressivo) ao tempo t através de um termo multiplicativo de correção de erros $\boldsymbol{\beta}^{\prime} \boldsymbol{y}_{\boldsymbol{t}-\mathbf{1}}$. Em geral há múltiplas relações entre $\boldsymbol{y}_{\mathrm{t}} \mathrm{e}$ os vetores $\alpha$ e $\beta$ são matrizes A e B, com cada coluna de B representando uma relação específica. O termo de correção de erros se torna $\boldsymbol{A B}^{\prime} \boldsymbol{y}_{\boldsymbol{t}-\mathbf{1}}=$ $\boldsymbol{C} \boldsymbol{y}_{\boldsymbol{t}-\mathbf{1}}$, que adicionado ao VAR gera o modelo VEC, conforme citado anteriormente (Enders 2010).

$$
\Delta \boldsymbol{y}_{t}=\boldsymbol{C} \boldsymbol{y}_{t-1}+\sum_{i}^{q} B^{\prime}{ }_{i} \boldsymbol{y}_{t-i}+\boldsymbol{\varepsilon}_{t}
$$

Se todas as variáveis em $\boldsymbol{y}_{\boldsymbol{t}}$ são I(1), os termos em diferenças são estacionários e o termo de correção de erros introduz a tendência estocástica de longo prazo. O posto da matriz $\boldsymbol{C}$ determina a dinâmica de longo prazo. Se $\boldsymbol{C}$ tem posto completo o sistema $\boldsymbol{y}_{\boldsymbol{t}}$ é estacionário em nível; se $\boldsymbol{C}$ tem posto 0 , o termo de correção de erros desaparece e o sistema é estacionário em primeiras diferenças; se $\boldsymbol{C}$ tem $0<$ posto $=\mathrm{r}<\mathrm{n}$, tem $\mathrm{r}$ relações de cointegração independentes entre $\boldsymbol{y}_{\boldsymbol{t}}$ nas matrizes $\boldsymbol{A}$ e $\boldsymbol{B} \operatorname{com} \boldsymbol{C}=\boldsymbol{A} \boldsymbol{B}$ '.

O teste de cointegração de Engle e Granger consiste em particionar $\boldsymbol{y}_{\boldsymbol{t}}$ em variável explicada $y_{1 t}$ e demais explicativas $\boldsymbol{x}_{\boldsymbol{t}}$, então fazer uma regressão entre estas variáveis e testar o grau de integração dos resíduos. Se estes forem estacionários existe evidência de cointegração entre as variáveis (Enders 2010).

Kapetanios et al. (2006) desenvolveram um teste de cointegração não linear baseado na generalização do teste de cointegração linear proposto por Engle e Granger (1987), em que os erros seguem um processo de transição suavizada globalmente estacionário. Usam uma estrutura de regressão para o mecanismo de correção de erros (ECM, Error correction mechanism) não linear exponencial de transição suavizada (ESTR , Exponencial Smooth transition regression framework).

Sob a hipótese nula de não cointegração contra a alternativa de globalmente estacionário com cointegração ESTR, o modelo testa a significância dos parâmetros que controlam o grau de não linearidade na velocidade de ajustamento. Seus testes propostos são teste $\mathrm{F}$ e teste $\mathrm{t}$ não lineares (os autores simulam as distribuições assintóticas via experimento de Monte Carlo).

O modelo proposto pelos autores está descrito na sequência. Seja um modelo de vetor de correção de erros não linear (VEC) com (n X 1) variáveis integradas de ordem 1, I(1), 
composto pelo processo estocástico $z_{t}$. Foram mantidas as notações dos autores, usando $z_{t}$ ao invés de $y_{t}$ para descrever o conjunto de variáveis no vetor a ser investigado por cointegração.

$\Delta \mathbf{z}_{\mathrm{t}=\boldsymbol{\alpha}} \boldsymbol{\alpha} \boldsymbol{\beta}^{\prime} \mathbf{z}_{\mathrm{t}-1}+\mathrm{g}\left(\boldsymbol{\beta}^{\prime} \mathbf{z}_{\mathrm{t}-1}\right)+\sum_{\mathrm{i}=1}^{\mathrm{p}} \Gamma_{\mathrm{i}} \Delta \mathbf{z}_{\mathrm{t}-\mathbf{i}}+\varepsilon_{\mathrm{t}}, \quad \mathrm{t}=1,2, \ldots, \mathrm{T}$,

$\boldsymbol{\alpha}(n X r), \boldsymbol{\beta}(n X n)$ e $\boldsymbol{\Gamma}_{i}$ são matrizes de parâmetros sendo que $\boldsymbol{\alpha}$ e $\boldsymbol{\beta}$ possuem posto completo de colunas e $\mathrm{g}: \mathbb{R}^{r} \rightarrow \mathbb{R}^{n}$ é uma função não linear. Um modelo VEC linear convencional, conforme representação de Engle e Granger (1987), é obtido escolhendo $\operatorname{g}\left(\boldsymbol{\beta}^{\prime} \boldsymbol{z}_{\boldsymbol{t}-\mathbf{1}}\right)=\mathbf{0}$ ou $g\left(\boldsymbol{\beta}^{\prime} \mathbf{z}_{t-1}\right)=-\boldsymbol{\alpha} \boldsymbol{\mu}^{\prime}$ onde $\boldsymbol{\mu}$ é um vetor $(n X 1)$ com parâmetros de nível.

De acordo com Kapetanios et al. (2006), mais recentemente, o teorema da representação de Granger tem sido estudado nos contextos dos modelos VEC não linear. Os autores, então, seguem Saikkonen (2005) e adotam as seguintes hipóteses:

Hipótese 1: (i) Os erros $\varepsilon_{t}$, em (1) são independentes e identicamente distribuídos, $\operatorname{iid}\left(0, \sum\right)$, sendo $\sum$ uma matriz $n X n$ definida positiva e $\mathrm{E}\left|\varepsilon_{\boldsymbol{t}}\right|^{l}<\infty$ para qualquer $1>6$. (ii) A distribuição de $\boldsymbol{\varepsilon}_{\mathrm{t}}$ em (1) é absolutamente contínua com respeito à medida de Lebesgue e possui densidade que é limitada entre zero e subconjuntos compactos de $\mathbb{R}^{n}$.(iii) As observações iniciais $\mathbf{Z}_{0} \equiv\left(\mathbf{z}_{-}, \ldots, \mathbf{z}_{0}\right)$ são dadas. (iv) Seja $\mathrm{A}(\mathrm{z})$ dado por $(1-z) \boldsymbol{I}_{\boldsymbol{n}}-\boldsymbol{\alpha} \boldsymbol{\beta}^{\prime} z-$ $\sum_{i=1}^{p} \Gamma_{i}(1-z) z^{i}$, se $\operatorname{det} \mathrm{A}(\mathrm{z})=0$ então $|\mathrm{z}|>1$ ou $\mathrm{z}=1$, onde o número de raízes unitárias são iguais a n-r. (v) g(.) é assintoticamente não maior que uma função linear de $\mathbf{x}_{\mathbf{t}}$. Sendo a decomposição $\mathbf{z}_{\mathrm{t}}=\left(\mathrm{y}_{\mathrm{t}}, \mathbf{x}_{\mathrm{t}}{ }^{\prime}\right)$, ou seja, uma variável explicada e as explicativas do modelo, respectivamente.

As hipóteses 1(i)-(iv) são básicas na literatura de cointegração e 1(v) lida com a não linearidade do modelo (1). A hipótese 1 garante que existe uma escolha de valores iniciais $\mathbf{z}_{-}$ p $, \ldots, \mathbf{z}_{0}$ tal que $\Delta \mathbf{z}_{t}$ e $\boldsymbol{\beta}^{\prime} \mathbf{z}_{\boldsymbol{t}-\mathbf{1}}$ sejam estritamente estacionários. Os autores se propõem, de maneira semelhante à metodologia de Engle e Granger, a investigar no máximo uma relação ${ }^{3}$ de cointegração de longo prazo entre $\mathrm{y}_{\mathrm{t}}$ e $\mathbf{x}_{\mathrm{t}}$. $\mathrm{O}$ foco é no modelo condicional da variável escalar $y_{t}$ sobre k-vetor $\mathbf{x}_{\mathrm{t}}(\mathrm{k}=\mathrm{n}-1)$ e os valores passados de $\mathbf{z}_{\mathrm{t}}$ e $\mathbf{Z}_{0}$. Reescrevendo a equação (2):

$$
\Delta \boldsymbol{z}_{t}=\boldsymbol{\alpha} \boldsymbol{\mu}_{t-1}+g\left(\boldsymbol{\mu}_{t-1}\right)+\sum_{i=1}^{p} \boldsymbol{\Gamma}_{i} \Delta \mathbf{z}_{t-1}+\boldsymbol{\varepsilon}_{t}, \quad \mathrm{t}=1,2, \ldots, \mathrm{T}
$$

Sendo $\boldsymbol{\alpha}$ um vetor $\mathrm{n} X 1$ de parâmetros de ajustamento e

$$
\mu_{t}=y_{t}-\boldsymbol{\beta}^{\prime}{ }_{x} \boldsymbol{x}_{t}
$$

\footnotetext{
${ }^{3}$ Para n variáveis podem existir n-1 relações estáveis de longo prazo entre elas.
} 
Sendo $\boldsymbol{\beta}_{x}$ um vetor $k X 1$ de parâmetros de cointegração. O segundo conjunto de hipóteses é descrito abaixo:

Hipótese 2 (i) A função não linear g(.) em (3) segue a forma funcional de transição suave exponencial $\mathrm{g}\left(\mu_{t-1}\right)=-\boldsymbol{\varphi} \mu_{t-1} e^{-\theta\left(\mu_{t-1}-c\right)^{2}}$,

assume-se que $\theta \geq 0$ para fins de identificação e $c$ é um parâmetro de transição. (ii)Particionando a matriz de coeficientes $\boldsymbol{\alpha}=\left(\xi, \boldsymbol{\alpha}_{x}^{\prime}\right)^{\prime}$ e $\boldsymbol{\varphi}=\left(\gamma, \boldsymbol{\varphi}_{x}^{\prime}\right)^{\prime}$ conforme $\boldsymbol{z}_{\boldsymbol{t}}=$ $\left(y_{t}, \boldsymbol{x}_{t}^{\prime}\right)^{\prime}$ tem-se $\boldsymbol{\alpha}_{\boldsymbol{x}}=\boldsymbol{\varphi}_{\boldsymbol{x}}=\mathbf{0}$. (iii) Não há cointegração entre o vetor de $k$ variáveis de ordem 1(1), $\boldsymbol{x}_{\boldsymbol{t}}$.(iv) $\xi<0$.

As hipóteses 2(ii) e (iii) implicam que o processo $\mathbf{x}_{\mathrm{t}}$ é fracamente exógeno e portanto o parâmetro de interesse em (7) são de variação livre a partir dos parâmetros em (8). As hipóteses 2(i) e (iv) implicam que a hipótese 1(v) é satisfeita e garantem que o mecanismo de correção de erro (não linear) em (3) é globalmente estacionário. Na prática, várias formas funcionais de $\mathrm{g}($.$) podem ser consideradas de modo a permitir a presença de ajustes de não$ linearidades no mecanismo de correção de erros, embora o foco dos autores seja o ESTR.

Na sequência, dividindo $\varepsilon_{t}$ de acordo com $z_{t}$, tem-se $\varepsilon_{t}=\left(\varepsilon_{y_{t}}, \boldsymbol{\varepsilon}^{\prime}{ }_{x_{t}}\right)^{\prime}$ e sua matriz de variância igual a $\boldsymbol{\Sigma}=\left(\begin{array}{cc}\sigma_{y y} & \sigma_{y x} \\ \sigma_{x y} & \sum_{x x}\end{array}\right)$, pode-se então expressar $\varepsilon_{\mathrm{yt}}$ condicionalmente nos termos de $\varepsilon_{x t}$ como $\varepsilon_{y t}=\sigma_{y x} \Sigma_{x x}^{-1} \varepsilon_{x t}+e_{t}, e_{t} \sim i i d\left(0, \sigma_{e}^{2}\right), \sigma_{e}^{2} \equiv \sigma_{y y}-\sigma_{y x} \sum_{x x}^{-1} \sigma_{x y}$, e $e_{t}$ é não correlacionado com $\boldsymbol{\varepsilon}_{x t}$ por construção. Substituindo (6) e (5) em (3), dividindo $\boldsymbol{\Gamma}_{i}=$ $\left(\gamma_{y i}^{\prime}, \Gamma_{x i}^{\prime}\right)^{\prime}$ com $i=1, \ldots, p$, definindo $\phi=\xi-\gamma$, e sob a hipótese 2 , obtem-se o modelo de regressão de correção de erros exponencial de transição suave (STR ECM) para $\Delta y_{t}$ e o modelo vetor de auto-regressão (VAR) marginal para $\Delta x_{t}$ :

$$
\begin{aligned}
& \Delta y_{t}=\phi \mu_{t-1}+\gamma \mu_{t-1}\left(1-e^{-\theta\left(\mu_{t-1}-c\right)^{2}}\right)+\boldsymbol{\omega}^{\prime} \Delta x_{t}+\sum_{i=1}^{p} \boldsymbol{\psi}_{i}^{\prime} \Delta z_{t-i}+e_{t} \\
& \Delta x_{t}=\sum_{i=1}^{p} \boldsymbol{\Gamma}_{x i} \Delta z_{t-i}+\boldsymbol{\varepsilon}_{x t} \\
& \boldsymbol{\omega} \equiv \sum_{x x}^{-1} \sigma_{x y} \mathrm{e} \quad \Psi^{\prime}{ }_{i} \equiv \gamma_{\gamma i}-\omega^{\prime} \Gamma_{x i}, i=1, \ldots, p . \text { Deve-se notar que (7) é uma }
\end{aligned}
$$

reparametrização de (3) sob a hipótese 2, que os autores usam para a construção do teste de co-integração, além disso, a hipótese 2(iv) implica que $\phi+\gamma<0$.

A equação (7) é forma não linear condicional do STR ECM e, de acordo com Kapetanios et al. (2006), faz sentido econômico porque em que muitos modelos econômicos prediz que o sistema subjacente tende a exibir um comportamento suave em direção a um atrator quando está suficientemente longe dele, embora mostre alguma instabilidade dentro de 
sua localidade. O modelo proposto satisfaz a hipótese 1 por meio da especificação do modelo por (7) e (8). Além disso, a aplicação do teorema 2 de Saikkonen ao modelo garante que existem valores iniciais $z_{\text {-p }}, \ldots, z_{0}$ tal que $\mu_{t-1}$ e $\Delta z_{t}$ sejam estritamente estacionários.

Em aplicações práticas diferentes ordens de defasagem para $\Delta y_{t}$ e $\Delta \boldsymbol{x}_{t}$ em (7) pode ser selecionado usando critérios de informação para a seleção - Akaike information criterion $(\mathrm{AIC})^{4}$ ou Bayesian information criterion (BIC) também conhecido por Schwarz criterion ${ }^{5}$ ou procedimentos de testes de significância sem perda de generalidade ou alteração na análise assintótica Ng e Perron (1995).

\subsection{Estratégia metodológica e teste para cointegração em modelos de correção de erro de transição suave não linear}

Os dados mensais de preços utilizados são os da IMS (International Medical Statistics) ${ }^{6}$ para o período de 2000 a 2009 dos medicamentos subclasse da Human musculoskeletal system categoria da classificação "The Anatomical Therapeutic Chemical (ATC) Classification System" usada para classificar medicamentos pela organização mundial da Saúde (WHO). Embora esta classificação, que reflete a área de atuação do medicamento no organismo, em si possa indicar um potencial mercado relevante, existe a possibilidade de não haver substituição entre os medicamentos de uma mesma classe dadas características específicas dos indivíduos tais como intolerâncias a certos princípios ativos (parte efetiva atuação do medicamento), grau de evolução da doença, combinações com uso de outros medicamentos e etc. Deste modo, ainda que 2 medicamentos pertençam a mesma subclasse terapêutica o seu mercado relevante precisa ser testado.

Para a análise de testes de preços foram escolhidos somente os medicamentos desta subclasse que são vendidos livremente nas farmácias e que, portanto, a decisão de consumo é do paciente e não do médico. Além disso, foram desconsiderados os medicamentos que saíram do mercado e os que entraram posteriormente a data de 2000, o que resultou em 7 séries de medicamentos. Para um mesmo medicamento com mais de uma apresentação considerou-se a o preço da apresentação de maior faturamento.

\footnotetext{
${ }^{4}$ Akaike (1974)

${ }^{5}$ Schwarz(1978)

${ }^{6}$ www.ims.com
} 
Como estratégia metodológica inicialmente testou-se o grau de integração das séries de preços dos medicamentos usando os testes Dickey-Fuller Aumentado e Phillips-Perron (ver anexo I). Os resultados mostram que as séries são integradas de primeira ordem.

Kapetanios et al.(2006) baseiam seu teste - sob a hipótese nula de não cointegração, $\mathrm{H}_{0}: \theta=0$, contra a alternativa de não linear ESTR cointegração, $\mathrm{H}_{0}: \theta>0$ - na dependência dos parâmetros de $\theta$ da equação 6 , onde $\theta$ determina as propriedades não estacionárias de $\mu$ t.

Seguindo a estratégia sugerida pelos autores, que por sua vez seguem Engle e Granger (1987), conduziu-se a estimação dos parâmetros do modelo em 2 estágios. No primeiro estágio,obtêm-seas estimativas dos resíduos:

$$
\hat{\mu}_{t}=y_{t}-\widehat{\boldsymbol{\beta}}^{\prime}{ }_{x} \boldsymbol{x}
$$

Sendo $\widehat{\boldsymbol{\beta}}_{\boldsymbol{x}}$ o estimador de mínimos quadrados ordinários (MQO) dos coeficientes $\boldsymbol{\beta}_{\boldsymbol{x}}$. No segundo estágio $\gamma$ em (6) não é identificado sob a hipótese nula e os autores linearizam o termo $\left(1-e^{-\theta\left(u_{t-1}-c\right)^{2}}\right)$ por uma expansão de série de Taylor de primeira ordem e permitem que $\phi \neq 0$ na hipótese alternativa, obtendo a seguinte regressão auxiliar de teste:

$$
\Delta \mathrm{y}_{\mathrm{t}}=\delta_{1} \hat{\mu}_{\mathrm{t}-1}+\delta_{2} \hat{\mu}_{\mathrm{t}-1}^{2}+\delta_{3} \hat{\mu}_{\mathrm{t}-1}^{3}+\boldsymbol{\omega}^{\prime} \Delta \mathbf{x}_{\mathbf{t}}+\sum_{\mathbf{i}=\mathbf{1}}^{\mathbf{p}} \boldsymbol{\psi}_{\mathbf{i}}^{\prime} \Delta \mathbf{z}_{\mathbf{t}-\mathbf{i}}+\text { error. }
$$

Sendo $\hat{\mu}_{t}=y_{t}-\widehat{\boldsymbol{\beta}}^{\prime}{ }_{\boldsymbol{t}} \boldsymbol{X}_{\boldsymbol{t}} \mathrm{o}$ resíduo de Mínimos Quadrados do primeiro estágio.

Em (2’) o número de defasagens i de $\llbracket \Delta z \rrbracket \_(t-i)$ é determinado pelo critério de informação de Akaike, estatísticas AIC e BIC (Box e Jenkins 1994). Para o caso das variáveis de preços de medicamentos da classe terapêutica química M01A1: ANTI-RHEUMATICS, NON-STEROIDAL.

Para testar a não cointegração contra a hipótese alternativa de cointegração não linear testa-se em (2') se conjuntamente, teste tipo-F, a restrição $\delta_{1}=\delta_{2}=\delta_{3}=0$ dada por:

$F_{N E C}=\frac{\left(S S R_{0}-S S R_{1}\right) / 3}{S S R_{0} /(t-4-p)^{\prime}}$

Sendo SSRoe $S S R 1$ a soma dos quadrados dos resíduos, respectivamente, com e sem impor as restrições $\delta_{1}=\delta_{2}=\delta_{3}=0$.

Razões teóricas, relacionadas a fenômenos econômicos específicos, levam alguns autores a usarem a restrição sobre o termo ao quadrado da equação (2'), reduzindo as equações (2') e (3') respectivamente a:

$$
\begin{aligned}
& \Delta \mathrm{y}_{\mathrm{t}}=\delta_{1} \hat{\mu}_{\mathrm{t}-1}+\delta_{2} \hat{\mu}_{\mathrm{t}-1}^{3}+\boldsymbol{\omega}^{\prime} \Delta \mathbf{x}_{\mathbf{t}}+\sum_{\mathbf{i}=\mathbf{1}}^{\mathbf{p}} \boldsymbol{\psi}_{\mathbf{i}}^{\prime} \Delta \mathbf{z}_{\mathbf{t}-\mathbf{i}}+\text { error } \\
& F_{N E C}^{*}=\frac{\left(S S R_{0}-S S R_{1}\right) / 2}{S S R_{0} /(T-3-p)^{\prime}}
\end{aligned}
$$




\section{Capítulo 3}

\section{Contextualização teórica de representação Visual}

\subsection{Técnicas de visualização: conceito geral}

A visualização de informação é tratada como auxiliadora no processo de análise e compreensão dos dados, através de representações gráficas manipuláveis que combinam conceitos de computação gráfica e Interação Homem Computador (SOUZA, 2007).

A visualização possui vários enfoques técnicos distintos, tais como Visualização Científica, Visualização de Informações, Visualização Estatística, Visualização de Processo, Visualização de Software entre outras. No entanto, todos os tipos de visualização compartilham o objetivo de transformar o dado em algo mais significativo, ou seja, uma representação visual útil de forma que o observador humano possa ter um melhor entendimento. Geralmente, essa transformação é realizada com o auxílio do computador através de recursos gráficos.

A VI(visualização da informação) pode ser utilizada em todas as áreas que apresentem grandes volumes de dados armazenados e que necessitem de análise dos mesmos. Pode ser aplicada em diversas áreas de conhecimento com diferentes enfoques como citado anteriormente. (SOUZA, 2007).

Considerando que dado é o conteúdo de um espaço de memória, sem significado e a informação é um dado associado a um significado (por exemplo: a palavra "fundamentos" quando mencionada fora de um contexto pode não ter significado, mas quando relacionada a um contexto como: o aluno que cursa a disciplina "fundamentos", a mesma palavra traz um significado). Considera-se então que a informação é tida como a matéria-prima para VI, isto é, define-se que os dados a serem visualizados têm algum significado ao usuário.

De acordo com Ware (2004 apud Neto, 2006) na computação gráfica, o termo ganha um significado mais abrangente não se atendo apenas aos mecanismos internos da maneira cognitiva de pensar e compreender certo dado. De uma construção interna da mente humana, a visualização torna-se também um artefato externo, apropriado para auxiliar em tomadas de decisão. 
Para essa transformação são utilizadas técnicas que mapeiam os dados em metáforas. A metáfora é uma figura de linguagem que transfere um termo para uma esfera de significado que não é a sua, com a finalidade de estabelecer representação do mundo por meio de analogias. Segundo Card et al.(1999, apud Santos, 2010) a VI é o uso de representação visual de dados abstratos para ampliar a cognição, de forma interativa e suportada por computador.

A filosofia da visualização de dados se dá por conta de sua interatividade, que possui várias opções de gráficos e é uniformemente melhor. Parte do processo interativo envolve em fazer transformações adequadas como logs, escolha da melhor forma para as variáveis analisadas ou até mesmo a remoção de alguma fonte variante, analisando o restante dos dados satisfatoriamente, considerando um esforço intelectual significativo. Também é parte dos processos interativos as diferentes formas de visualização dos dados através de várias técnicas gráficas. Nesse âmbito, vários autores descrevem "scripts" para serem aplicados nas ferramentas de visualização, tornando uma ajuda aos pesquisadores.

A visualização de informações procura reunir o poder da percepção visual humana com o poder de processamento do computador moderno para que um conjunto de dados possa ser analisado e compreendido rapidamente, combinando assim aspectos da visualização científica, interfaces homem-computador, mineração de dados, processamento de imagens e computação gráfica para efetivamente conseguir uma representação gráfica visual de dados abstratos que se encontram de alguma maneira, armazenados numa base de dados (CARD et al., 1995 apud Santos, 2010). As mais diversas maneiras de se representar os dados e/ou resultados de estudos permitem que a visualização das informações beneficie diversas áreas, cada uma mantendo suas características de suas informações.

De acordo com Berti (2004), alguns dados são facilmente representados, pois já possuem um padrão gráfico. Entretanto, outros não possuem esse referencial, por isso são denominados dados abstratos. O interesse e a necessidade de representá-los originou uma linha de pesquisa dentro da Visualização, denominada Visualização de Informação ou técnica de VI. O desafio então fica por conta do desenvolvimento de ferramentas que atendam à necessidade de representar dados de maneira simples e, ao mesmo tempo, intuitiva.

Atualmente, com a demanda de uso da internet, também a visualização de informação toma destaque nesse campo. Muitos usuários apresentam dificuldades na navegação em websites em busca de informações, remetendo, por exemplo, a disponibilização de mapa do site. As grandes quantidades de informações tornam dificultosos os caminhos para recuperar os traçados percorridos até uma determinada página (SOUZA, 2007). Nesse trabalho citado, o 
termo visualização também é considerado algo visível, no sentido de visualizar uma imagem mental e figurá-la, transformando conceitos abstratos em imagens reais, tendo como meta a VI o uso de representações visuais, interativas e suportadas por computador, auxiliando assim o processo de análise e compreensão dos dados, através de representações gráficas manipuláveis, tornando assim possível transformar o dado em algo mais significativo, ou seja, uma representação visual útil de forma que o observador humano possa ter um melhor entendimento.

\subsection{Modelos de visualização de dados estatísticos multivariados}

Muitas análises estatísticas envolvem apenas duas variáveis: Uma variável preditora e uma variável de resposta. Tais dados se tornam fáceis de visualizar utilizando um gráfico de dispersão (conhecida como 'scatterplot'), do tipo, histogramas bivariados, boxplots, entre outros. Também é possível visualizar os dados trivariados com gráficos de dispersão em 3D, 2D e gráficos de dispersão com uma terceira variável representada por cor, por exemplo.

Entretanto, muitos 'datasets' envolvem um número significativo de variáveis, tornando a visualização direta muito mais trabalhosa. Por isso, a visualização de dados multivariados se torna ideal para uma matriz de dados sendo $n X p$ onde as linhas representam as observações e as colunas representam as variáveis. As variáveis são demonstradas como sendo $X_{1}, X_{2}, \ldots, X_{p}$.

No contexto da pesquisa atual realizada por engenheiros, estatísticos e outros envolvidos em mineração de dados, a visualização de dados multivariados vem se tornando cada vez mais uma área interessante a ser explorada.

Vários autores destacam atualmente a abrangência de software que exploram em profundidade a visualização de dados multivariados.

Para dados bivariados e multivariados, do ponto de vista da visualização técnica dos gráficos, dados bivariados são muito mais fáceis de se entender, mesmo com dados dimensionais muito grande, o que torna interessante sua visualização em projeções dimensionais.

A técnica conhecida como "scatterplot" é bastante utilizada para as plotagens suavizadas para análise de X1 x X2 e vice-versa, no caso de visualização bivariada. 
Histogramas e "boxplot" também são utilizados, se bem que o "scatterplot" é recomendado para dispersões maiores de dados.

O uso da ferramenta MatLab® se torna interessante por possibilitar vários tipos de plotagens como:

I. MATRIZES DE DADOS ESPALHADOS (SCATTERPLOT): Esse tipo de técnica mostra aos pares dados espalhados na superfície entre as variáveis estabelecidas em uma forma matricial e são equivalentes a uma projeção dos dados para todos os pares de eixos de coordenadas. Quando o valor de p é grande, as representações de matrizes 'scatterplot' podem se tornar inviáveis, nesse caso podendo ser representadas apenas as correlações entre as variáveis, utilizando elipses. Como exemplo, será carregado um dataset 'default' com o nome 'carbig', um dataset que contém diversas variáveis mensuráveis de aproximadamente 400 veículos automobilísticos compreendidos entre os anos 70 e anos 80, retirado das telas de ajuda do MatLab®. Com isso, é possível uma visualização multivariada usando os valores de eficiência de combustível (em milhas por galão, MPG), aceleração (tempo de 0 a 60 MPH em segundos), deslocamento de motor (em polegadas cúbicas), peso e pôtencia-cavalo. Foi usado o número de cilindros para agrupar as observações. Logo abaixo, os comandos que foram utilizados no MatLab®, para gerar as representações:

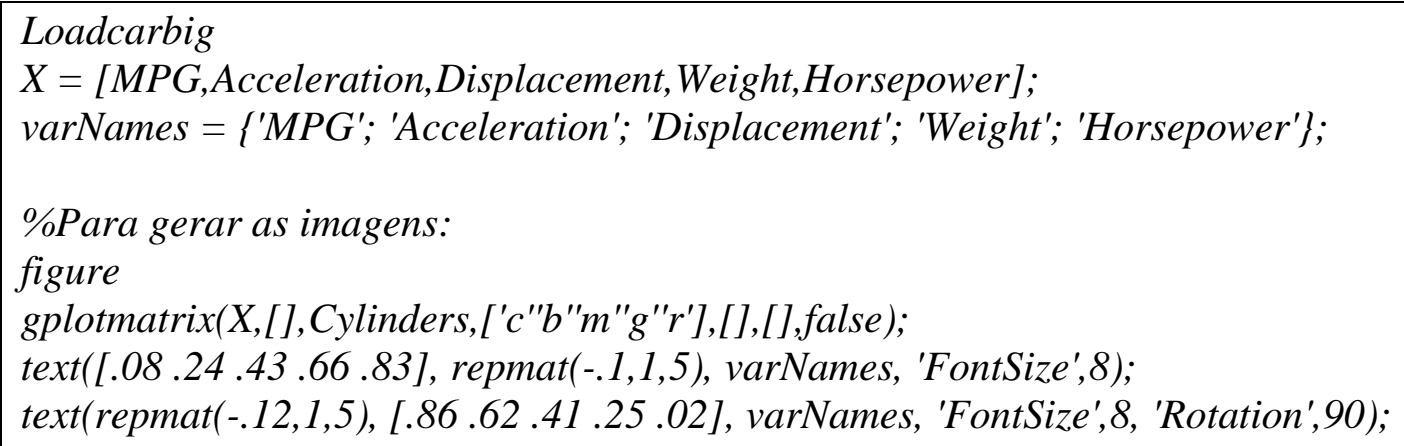




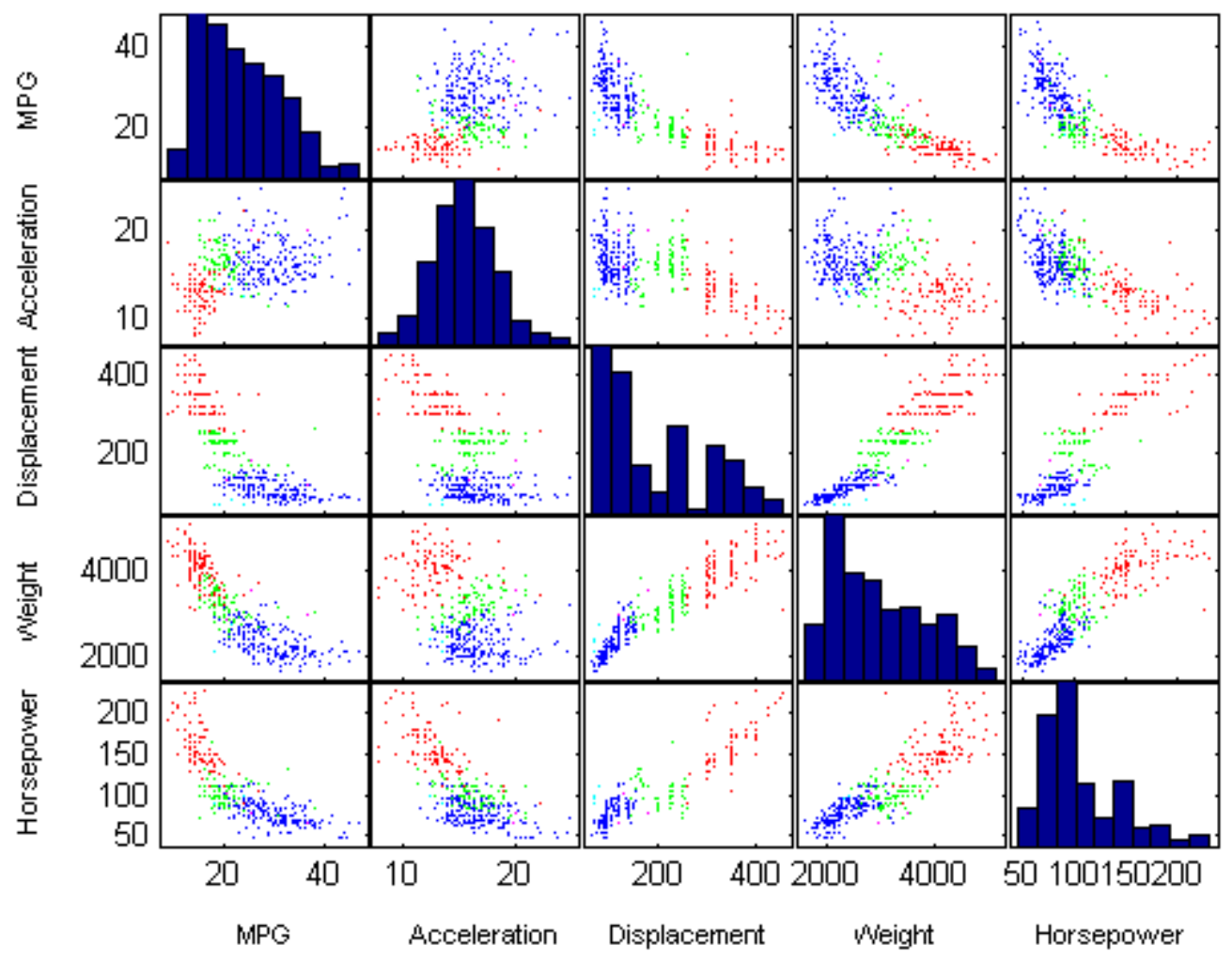

Figura 01 - Exemplo de uma representação ScatterPlot

Os pontos em cada 'scatterplot' são codificados de acordo com as cores por números de cilindros: azul para 4 cilindros, verde para 6 e vermelho para 8. Há também um punhado de carros de cinco cilindros e os carros com motor rotativo está listada como tendo três cilindros. Este conjunto de 'plots' facilita a escolher padrões nas relações entre pares de variáveis. No entanto, padrões importantes nas dimensões mais elevadas, poderão não serem reconhecidas nessa plotagem.

II. POINTS CLOUDS: Através da movimentação de rotação pelo mouse, as visualizações no MatLab® podem se tornar interessantes para demonstrar os valores de rotação dos pontos flutuantes e detectar uma estrutura de informação de numeração randômica. Numa estrutura multivariada, quartilhos podem ser demonstrados por cores;

III. ESTIMAÇÃO DE DENSIDADE MULTIVARIADA: Existem diversos autores que propõe formas de visualização de resultados por densidade multivariada. São propostos visualizações univariadas ou bivariadas. Através de uma implementação 
computacional e estatística eficiente pode se obter estimações de densidade multivariada usando histogramas por média (conhecido como 'ASH'). Ferramentas como S-Plus ou ' $R$ ' apresentam uma eficiência de resultados com a implementação de codificações em linguagem ' $\mathrm{C}$ ';

IV. COPLOT: Pode ser entendido como plotagens coordenadas. Propõe, segundo estudos de alguns autores, mais eficiência e demonstra uma grande quantidade de informação do que matrizes 'scatterplot' ou '3D point Clouds'. A ideia básica do 'coplot' é produzir uma visualização multipainel altamente coordenada de gráficos de dispersão, muitas vezes reforçada por uma transição suave como 'loess'. Um subconjunto dos dados é representada em cada painel para um intervalo fixo de valores das variáveis indicadas. Dadas as variáveis utilizadas nos painéis adjacentes que se sobrepõem, proporcionando uma transição suave entre os painéis;

V. ANDREWSPLOT: Trata de uma plotagem "Andrews" de dados multivariados. Na sintaxe 'andrewsplot(X)' é criado uma plotagem “Andrews" de uma matriz X para visualizar a estrutura dos dados em alta dimensão. $O$ formato da representação das altas dimensões é em curva. Na matriz $\mathrm{X}$ as linhas representam as observações e as colunas, as variáveis. Andrews plot representa cada observação de uma função $f(t)$ de um modelo variável contínuo ' $t$ ' no intervalo [0,1]. A função ' $\mathrm{f}(\mathrm{t})$ ' é definida para a iésima observação em X como:

$$
f(t)=X(i, 1) / \sqrt{2}+X(i, 2) \sin (2 \pi t)+X(i, 3) \cos (2 \pi t)+\cdots
$$

Cada função é uma série 'Fourier', com coeficientes iguais aos valores da observação correspondente. Um exemplo retirado do aplicativo MatLab® pode ser visto na figura abaixo, junto com a base de dados:

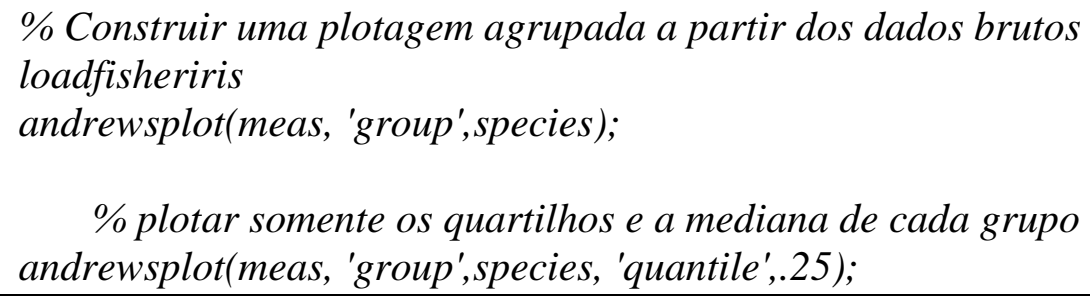




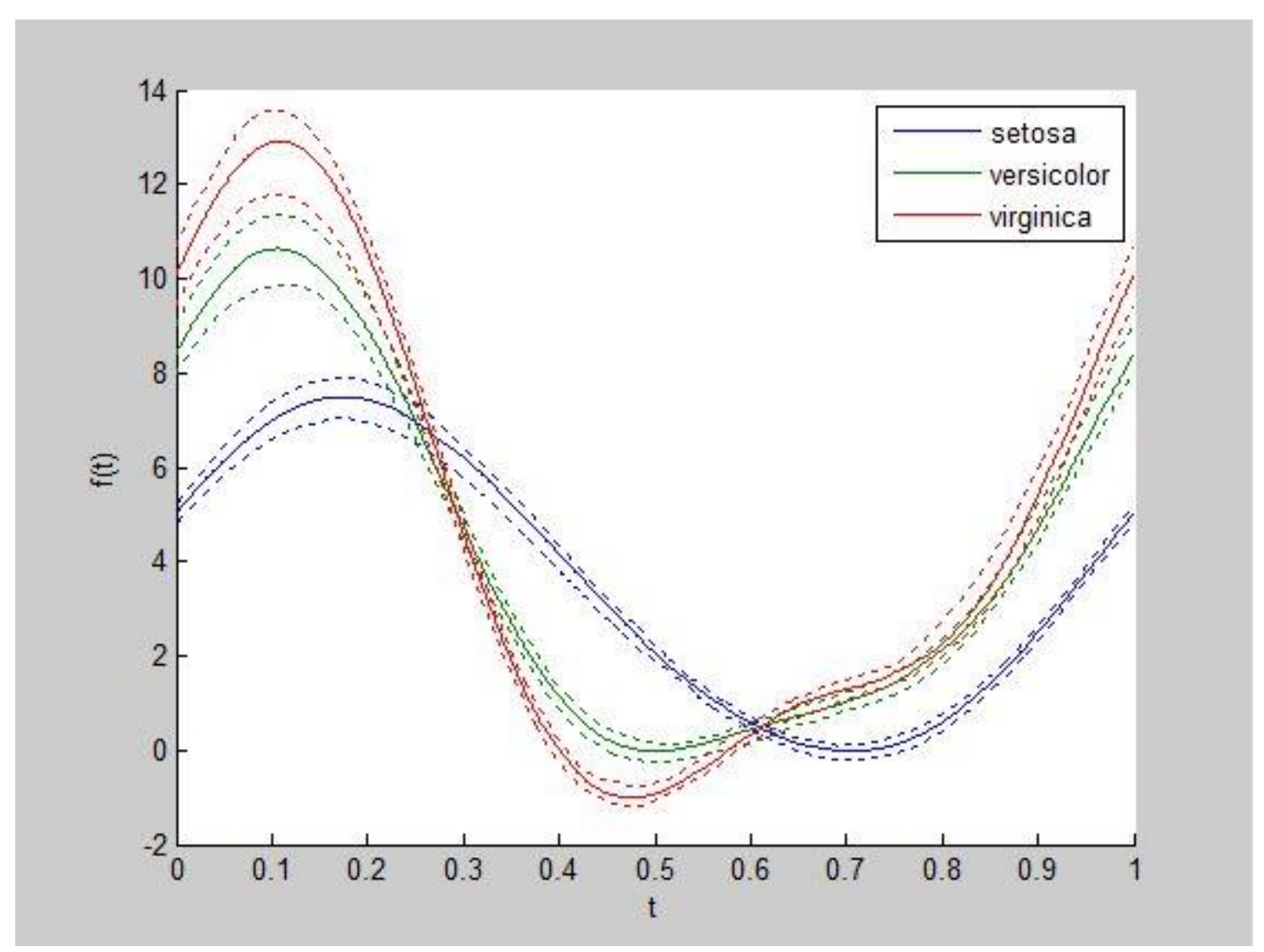

Figura 02 - Andrews plot mostrando a mediana e $1^{o}$ quartilho de uma base de dados agrupada

VI. PLOTAGEM GLYPHPLOT: Também para representar dados multivariados, mas só que agora baseado em plotagens de estrelas ou faces de Chernoff. Esse recurso cria uma plotagem de faces a partir de dados multivariados de uma matrix X N por P. As linhas representam as observações e as colunas, as variáveis. Cada estrela (ou face) representa cada observação onde o i-ésimo raio é proporcional ao comprimento da iésima coordenada daquela observação. Um exemplo também retirado das páginas de ajuda do MatLab® pode ser observado, com seus comandos, abaixo:

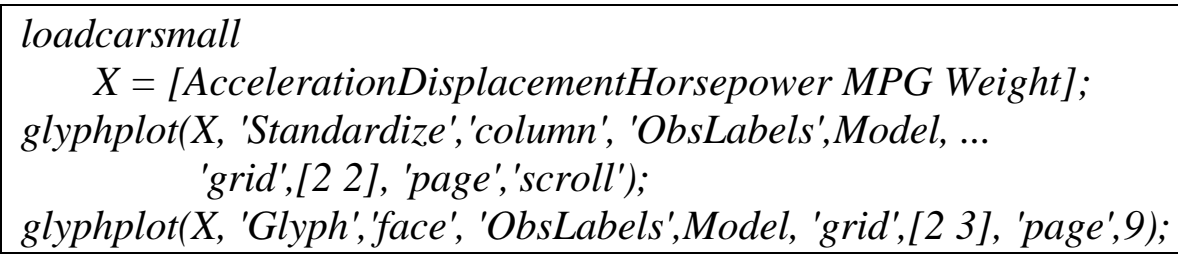




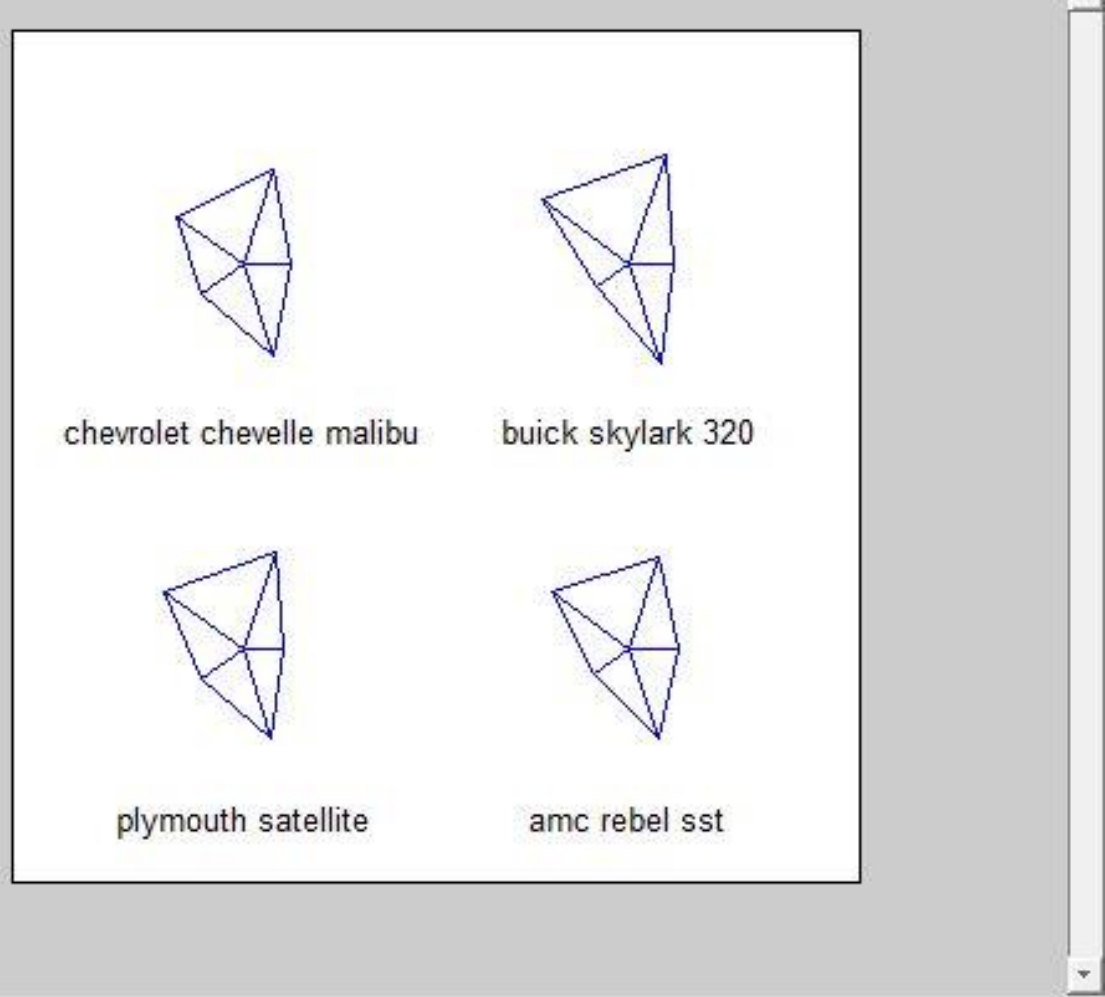

Figura 03 - Glyphplot mostrando os dados agrupados com desenho de estrela



Figura 04 - Glyphplot mostrando os dados agrupados com desenho de face 
VII. PLOTAGEM DE COORDENADAS PARALELAS: Plotagem de coordenadas paralelas para análise de dados multivariados foi implementado por Wegman (1990) e posteriormente discutido por Wegman e Carr(1993). Os eixos de coordenadas são representadas como linhas paralelas e um segmento de linha agrupa cada valor. Entretanto, assim que o tamanho da amostra aumenta o enredo tende a se tornar mais turvo. Mesmo assim, as plotagens por coordenadas paralelas podem se tornar muito atraentes nas interpretações das informações. O MatLab® apresenta um método de visualização de coordenadas paralelas que se torna interessante por trabalharmos com série longa de preços. Nas áreas de ressonância magnética e ultrassonografia, muitos dados multidimensionais são gerados e aplicados recursos para suas interpretações. Satélites de sensoriamento remoto estão disponibilizando ultimamente muitos dados multivariados, tornando incentivador a aplicação de resultados de visualização multidimensional para interpretação desses dados, por isso foi o modelo mais adequado dentre os exemplos apresentados para a representação de nossas informações. Um outro exemplo, retirado do histórico de ajuda do MatLab®, demonstra, através de um agrupamento de dados brutos, em 2(duas) figuras, a plotagem de coordenadas paralelas desses dados, agrupados e também a mediana e o quartilho desses dados. Os comandos para gerar os 2(dois) gráficos abaixo foram:

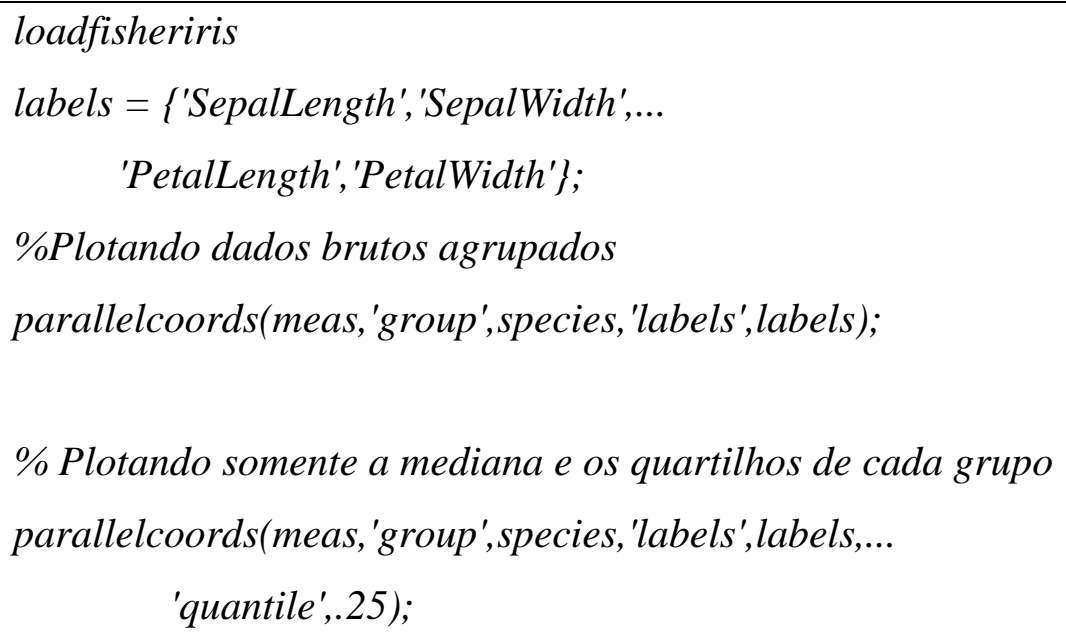






Figura 05 - Dados brutos agrupados

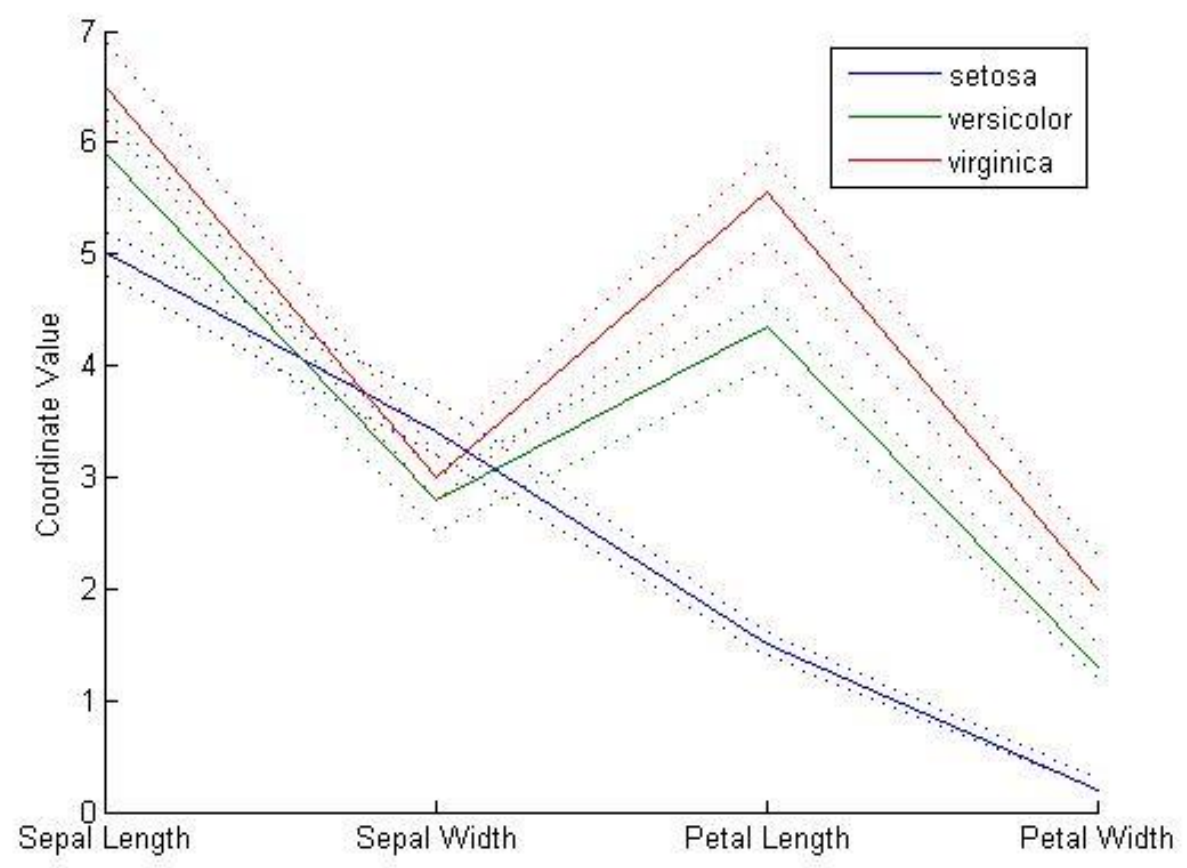

Figura 06 - Plotando somente a mediana e os quartilhos de cada grupo 
Uma observação a ser feita sobre os dados, os mesmos se encontram na base de exemplos do MatLab®, ao executar o comando "loadfisheriris" é possível observar as matrizes com seus respectivos valores que geraram os gráficos acima.

Pelas características multivariadas apresentadas pela plotagem de coordenadas paralelas é que foi decidido nesse trabalho usá-la como representação visual para a interpretação dos dados, dando assim um grau de liberdade maior ao usuário quando da escolha das variáveis ao qual se deseja estudar.

\subsection{Trabalhos Correlatos}

Antes de se iniciar o desenvolvimento da aplicação, uma busca nas ferramentas de pesquisas como "Google Acadêmico", "IEEE Digital Library" e biblioteca virtual da "USP" foi realizada no período de agosto a dezembro de 2013, com o intuito de encontrar trabalhos correlatos, mais especificamente trabalhos associados com determinação de mercado relevante e uso da ferramenta MatLab®. Foi possível encontrar trabalhos relacionados à utilização do MatLab®, mais especificamente a ferramenta “Guide", que permite construções de visualizações para diversos segmentos, porém um assunto diretamente relacionado a determinação de mercado relevante utilizando o MatLab® com ferramenta "Guide" não foi encontrado.

Ao todo, foram relacionados 11 (onze) trabalhos, compreendidos entre artigos e trabalhos de conclusão de curso. Para encontrar esses artigos relacionados, foram utilizadas as seguintes combinações de palavras chave na busca: "Guide", "mercado relevante", "economia", "MatLab".

Essas buscas representaram 72,73\% de resultado positivo para o uso do MatLab® e mais especificamente, uma tela de visualização de resultados através do recurso do "Guide". Três trabalhos não apresentaram relação com a ferramenta em questão, um tratava assunto sobre correlação, mas sem qualquer ponto em comum com mercado relevante, o outro era sobre análise de bolhas em pulmões, apresentando apenas alguns gráficos padrões da ferramenta sem qualquer relação com nosso trabalho e o terceiro tratava visualização em 3D para hipocampo cerebral, mas a referência foi apenas em uma pequena interface desenvolvida no aplicativo para auxiliar outra ferramenta, conhecida como biblioteca gráfica Visualization Toolkit (VTK).

Abaixo, é possível analisar a tabela com os títulos e autores desse resultado de busca. 


\begin{tabular}{|c|c|c|}
\hline TITULO & AUTOR(ES) & ÁREA DE PESQUISA \\
\hline $\begin{array}{c}\text { AVASS - AMBIENTE VIRTUAL } \\
\text { DE APRENDIZAGEM DE } \\
\text { SINAIS E SISTEMAS }\end{array}$ & ZILMAR DE SOUZA JUNIOR & $\begin{array}{c}\text { TELECOMUNICAÇÕES: SINAIS } \\
\text { E SISTEMAS }\end{array}$ \\
\hline $\begin{array}{c}\text { APLICAÇÃO DO GUIDE DO } \\
\text { MATLAB NA REDUÇÃO DE } \\
\text { CÔNICAS }\end{array}$ & $\begin{array}{c}\text { ALISSON GADELHA DE } \\
\text { MEDEIROS }\end{array}$ & $\begin{array}{c}\text { MATEMÁTICA: RESOLUÇÃO } \\
\text { DE EQUAÇÕES CÔNICAS }\end{array}$ \\
\hline $\begin{array}{c}\text { UTILIZAÇÃO DO MATLAB } \\
\text { COMO FERRAMENTA DE } \\
\text { DESENVOLVIMENTO E DE } \\
\text { VISUALIZAÇÃO } \\
\text { GRÁFICA DUM PROGRAMA } \\
\text { DE ANÁLISE DE ANTENAS } \\
\text { PELO MÉTODO DE FDTD }\end{array}$ & $\begin{array}{c}\text { NASSRI ABOKHALAF, } \\
\text { CLÁUDIO MARTINS, PEDRO } \\
\text { PINHO, J. F. ROCHA PEREIRA }\end{array}$ & $\begin{array}{c}\text { TELECOMUNICAÇÕES: } \\
\text { ANTENAS }\end{array}$ \\
\hline $\begin{array}{c}\text { DESENVOLVIMENTO DE } \\
\text { FERRAMENTA } \\
\text { COMPUTACIONAL PARA } \\
\text { CONFIGURAÇÃO DE SISTEMA } \\
\text { DE ENSAIO ULTRASSÔNICO, } \\
\text { AQUISIÇÃO E } \\
\text { PROCESSAMENTO DE SINAIS }\end{array}$ & $\begin{array}{c}\text { IGOR RIBEIRO; LÍLIAN SILVA; } \\
\text { CLÁUDIA FARIAS; EDUARDO } \\
\text { SIMAS FILHO ; ELMO BORGES } \\
\text { JUNIOR }\end{array}$ & $\begin{array}{c}\text { TELECOMUNICAÇÕES: SINAIS } \\
\text { ULTRASSÔNICOS }\end{array}$ \\
\hline $\begin{array}{c}\text { DESENVOLVIMENTO DE UM } \\
\text { AMBIENTE DE CONTROLE } \\
\text { E MONITORAMENTO EM } \\
\text { TEMPO REAL } \\
\text { USANDO O MATLAB E A } \\
\text { PLACA DE AQUISIÇÃO } \\
\text { NUDAQ PCI-9112 }\end{array}$ & $\begin{array}{c}\text { HUGO TANZARELLA } \\
\text { TEIXEIRA }\end{array}$ & ELETRÔNICA \\
\hline $\begin{array}{c}\text { ESTUDO DO IMPACTO DA } \\
\text { INTRODUÇÃO DOS VEÍCULOS } \\
\text { ELÉTRICOS NOS PREÇOS DE } \\
\text { MERCADO E NOS } \\
\text { DIAGRAMAS DE CARGA }\end{array}$ & $\begin{array}{c}\text { RICARDO NUNO LOUREIRO } \\
\text { GONÇALVES }\end{array}$ & LOGÍSTICA \\
\hline $\begin{array}{c}\text { PROCESSAMENTO DE SINAIS } \\
\text { DE ECG PARA GERAÇÃO }\end{array}$ & $\begin{array}{l}\text { CAMILA B. SOUZA, RODRIGO } \\
\text { V. ANDREÃO, MARCELO V. }\end{array}$ & MEDICINA \\
\hline
\end{tabular}




\begin{tabular}{|c|c|c|}
\hline AUTOMÁTICA & SEGATTO & \\
DE ALARMES & & \\
\hline FSO. TUTORIAL SOBRE A & JOSÉ FRANCISCO MEIRELES & TELECOMUNICAÇÕES: SINAIS \\
CONSTRUÇÃO DO SOFTWARE & A. JUNIOR & ÓPTICOS \\
PARA ENLACES ÓPTICOS & & \\
\hline
\end{tabular}

Tabela 02 - Trabalhos correlatos usados como referência

JUNIOR(2011) descreve o Ambiente Virtual de Aprendizagem de Sinais e Sistemas (AVASS) como um ambiente virtual para aprendizagem autônoma dos conteúdos curriculares desenvolvidos nas ementas da área de Sinais e Sistemas. Dispondo de módulos aquisição, amostragem, quantização e codificação de sinais com operações básicas realizadas sobre sinais como, multiplicação por escalar, deslocamento no tempo, escalamento temporal, reversão temporal de sinais, multiplicação de sinais e soma de sinais, representação de sinais no domínio do tempo e domínio da frequência, modulações analógicas em AM e FM, modulações digitais em ASK, PSK e FSK e codificação de sinais em NRZ, RZ, AMI e Manchester. Todas essas técnicas são representadas através de interfaces gráficas padronizadas, que permitem a exploração dos temas pelo usuário em um ambiente interativo e flexível, desenvolvido no Matlab®, provendo compatibilidade em diferentes sistemas operacionais além de ser uma plataforma de desenvolvimento muito utilizada na área de Telecomunicações. No capítulo 3 de seu trabalho de monografia do curso de tecnologia, o autor aborda com mais ênfase o recurso "guide" na construção das janelas interativas, onde ele ressalta o trabalho desenvolvido em duas etapas, sendo a primeira construção do ambiente gráfico e a segunda etapa o desenvolvimento do código. As junções dessas duas etapas geraram como resultado visualização através de gráficos e interações através de botões.

MEDEIROS (2011) apresenta em seu trabalho de conclusão de curso, de forma didática, a classificação de uma cônica usando a função "Guide” do Matlab®, a qual proporciona a construção de caixas interativas (interface gráfica) que através da configuração de seus controles, por meio de uma linguagem de programação, permite a classificação, novo centro, equação reduzida e a visualização gráfica da cônica. O programa foi desenvolvido usando essencialmente, os coeficientes da equação geral da cônica. Assim, é possível obter de forma fácil e rápida a classificação de uma cônica qualquer. É necessário que o usuário, ao manipular o programa, ingresse os valores dos coeficientes da equação geral da cônica. É 
abordado em seu trabalho o funcionamento do MatLab®, do Guide e um capítulo específico é dedicado a explicar o funcionamento da aplicação.

O artigo escrito por Abokhalaf (2002), apesar de tratar de uma versão um pouco mais antiga do MatLab® (versão 5.3), não perde a base teórica dos comandos e, nesse artigo, ele apresenta o uso do MatLab® e da ferramenta Guide para o desenvolvimento de um programa para o desenho e simulação de antenas baseado no método FDTD (Finite Difference Time Domain) e também para a visualização da estrutura e dos resultados obtidos após a sua simulação. Em detalhes, o artigo apresenta a descrição do recurso "Guide", com os resumos programáveis atribuídos ao sistema em questão. Como dito, a versão do MatLab® é antiga, as telas apresentadas não condiz com a versão que foi utilizada nesse trabalho (versão 2013a8.1.0.604), mas a base programável é imutável, podendo ser considerada em qualquer versão. O programa teve por objetivo desenhar antenas simples e simular seu comportamento.

RIBEIRO (2013) apresenta em seu artigo sobre um ensaio não destrutivo ultrassônico, a ferramenta MatLab® como ferramenta utilizada no desenvolvimento computacional para a configuração do ensaio. Sua fundamentação teórica no uso da ferramenta MatLab® se dá por conta que o caráter matricial da representação de dados no Matlab® e a existência de inúmeras funções para manipulação demonstram a capacidade de se tratar sinais de forma simples, sendo notável a facilidade em se criar rotinas computacionais ou expandir a funcionalidade das funções existentes, de forma a encontrar soluções numéricas adequadas à aplicação nas mais distintas áreas do conhecimento, incluindo pesquisa, projeto e processamento de sinais.

Também como forma de atender à necessidade de permitir acesso rápido e direto a rotinas implementadas anteriormente, são desenvolvidas interfaces gráficas, que são o ponto de contato ou método de interação entre uma pessoa e um programa, a fim de trocarem informações. É onde os autores do artigo encontram subsídios para definir a aparência e a facilidade de uso do computador utilizando o MatLab® com a interface gráfica. Desta forma, o Matlab® reúne habilidade de desenvolver aplicações gráficas que desfrutam de vasta biblioteca matemática. As telas permitem configurar o sistema ultrassônico, realizar processamento digital de sinais e coletar sinais.

TEIXEIRA (2008) em seu trabalho de graduação descreve seu principal objetivo o desenvolvimento de uma solução em MatLab® para controlar um processo em tempo real utilizando uma placa de aquisição de dados NUDAQ PCI-9112. Compreendeu o desenvolvimento do programa que faz a comunicação entre a placa de aquisição e o 
MATLAB®, mais o algoritmo de controle PID em tempo real, e a implementação da interface gráfica que permite a visualização de gráficos em tempo real do set point e da variável de saída e a inserção dos parâmetros de controle. Como principais recursos, foram utilizados a placa NuDAQ PCI-9112, para aquisição de dados, em conjunto com o toolbox DAQ-MTLB para o MATLAB, ambos da Adlink. Apesar de ser um trabalho voltado para a engenharia elétrica, não tendo qualquer relação com o nosso projeto de mercado relevante, o que tornou esse trabalho interessante foram as formas de programação no "guide" utilizada pelo autor, estruturas computacionais bastante semelhantes à nossa construção. O trabalho também mostra, em detalhes, comandos utilizados, que apresentam uma lógica estrutural também utilizada para o desenvolvimento interativo do nosso projeto. Através de botões, labels, caixas de textos e outras ferramentas comuns da interface "guide" foi possível construir uma tela de interação com o usuário bastante didática, tarefa essa realizada em nosso projeto. Além de toda a explicação técnica, o autor destacou em um apêndice os principais comandos computacionais utilizados no sistema desenvolvido.

GONÇALVES (2012), em seu trabalho, apresenta uma interface gráfica para a entrada e saída dos dados, baseada em gráficos, utilizando o "Guide" do MatLab. No início da leitura desse trabalho foi difícil identificar de qual ferramenta gráfica o autor se referia, porque somente no capítulo 5, item 4, é que se faz uma breve abordagem a respeito do uso do “Guide”. Foi possível observar a semelhança do ambiente pelas imagens do trabalho, mas a conclusão que se tratava do MatLab foi possível somente após a leitura do capítulo 5. Entretanto, se tornou interessante referenciar esse trabalho aqui, justamente para mostrar a flexibilidade com outros ambientes que necessitam cálculos matemáticos e matriciais, independente se tem ou não relação com o nosso tema, o estudo do mercado relevante. $\mathrm{O}$ trabalho de dissertação do autor, que no momento da consulta se apresentava como "provisório" é bastante extenso dentro do tema proposto, ou seja, o impacto dos veículos elétricos nos preços de mercado.

Um outro artigo relacionado diretamente com visualização utilizando a ferramenta “Guide” oferecida pelo MatLab® é o processamento de sinais ECG descrito por SOUZA (2006), onde este trabalho consiste na implementação e integração de rotinas de análise de sinais ECG em ambiente MATLAB, tendo em vista uma aplicação para geração automática de alarmes associados a situações de risco do coração. O sistema concebido se insere num projeto de tele-monitoramento ambulatorial da atividade elétrica do coração de pacientes mantidos em domicílio, tendo um sistema basicamente composto por uma base de dados 
contendo os registros de ECG necessários para as simulações dos algoritmos para gerar resultados de segmentação e classificação dos sinais de ECGe a interface GUI que permite o usuário executar os algoritmos e exibir os resultados de classificação que são exibidos numa saída gráfica para que o usuário possa interpretá-las. Apesar de não ter relação alguma com determinação de mercado relevante, esse artigo mostrou que o resultado de visualização desenvolvido pela ferramenta constrói uma boa interface de interpretação de resultados, o que é proposto em nosso trabalho.

JUNIOR (2012) em seu tutorial descreve um procedimento de pesquisa a respeito de uma construção de software para enlaces ópticos, que surgiu através de várias versões betas, onde o propósito do software é a construção de uma interface amigável através do MatLab com o uso da ferramenta "Guide", para a realização do balanço de potência em análises FSO. Nas três versões descritas, o autor apresenta as diversas opções que o usuário tem para o preenchimento dos valores a serem calculados, cálculos esses que necessitam ser precisos. A justificativa da escolha do "Guide" do Matlab se deu por conta da linguagem de programação com muita versatilidade e bem simples para trabalhar, além de contar com diversas funções já definidas, dispensando dessa maneira a declaração de variáveis, algo comum e padrão em muitas linguagens de programação.

O que chamou a atenção nesse trabalho, comparando ao nosso trabalho de determinação de mercado relevante é a necessidade de sua interatividade com o usuário, passando padrões, efetuando cálculos precisos e demonstrando graficamente os resultados, por isso foi considerado relevante comentar a similaridade da lógica e da escolha da ferramenta, em relação ao trabalho desenvolvido nessa dissertação.

Mais uma vez vale ressaltar que dos trabalhos pesquisados e relacionados aqui, o que é importante assimilar são as justificativas pela escolha do MatLab e sua ferramenta de construção de interface, que vão de encontro com nossas justificativas.

\subsection{Contribuições na área de visualização}

Neste trabalho foi desenvolvido um ambiente virtual visando ilustrar, de forma sucinta, os princípios práticos para determinação de mercado relevante. A implementação foi realizada com o auxílio da plataforma de desenvolvimento fornecida pelo software Matlab® que se mostrou confiável e potente para esta finalidade. O próprio SITEMERE (Sistema de Teste de Mercado Relevante - nome dado a esse sistema desenvolvido) serve de referência 
para futuras funcionalidades facilitadoras do processo de ensino-aprendizagem. Podendo dar continuidade na área de trabalho de economia, auxiliando pesquisadores ligados diretamente no assunto, assim como permitir à área de sistemas de informação. 


\section{Capítulo 4}

\section{Desenvolvimento da representação Visual}

\subsection{Visualização de informação (VI) construída através da ferramenta MatLab®}

Os ambientes de programação quantitativos, também conhecidos como QPE (Quantitative Programming Environments) é um ambiente de programação abrangente que normalmente possui os recursos necessários para a realização da exploração dos dados e visualização, proporcionam capacidades de documentações, cálculos além de proporcionar uma visualização de dados iterativos e exploratória.

O QPE é tratado por alguns autores como sendo um ambiente computacional adequado que permite aos pesquisadores reproduzirem facilmente os resultados com suas respectivas publicações (MCLEOD, 2001).

Através das revisões bibliográficas realizadas, expostas de forma reduzida anteriormente, foi possível observar que a ferramenta MatLab apresenta várias formas de representação visual para tratar visualizações multidimensional, o que mantém suas ligações diretas com o proposto dessa dissertação, porque a visualização de mercado relevante trata visualizações multivariadas. Porém, como citado anteriormente, não foi encontrado uma ferramenta disponível e já desenvolvida para a área de economia, mais precisamente na área de determinação de mercado relevante. Isso motivou a escolha da ferramenta do MatLab® porque essa ferramenta é muito difundida na área econômica e também na área acadêmica, observando aí uma ótima oportunidade do uso desse ambiente, que já é familiar aos especialistas das áreas econômicas, tornando assim fácil sua adaptação para uso na determinação de mercado relevante e também procurando deixar o ambiente mais interativo para profissionais da área de antitruste, advogados e outros.

O MatLab® é uma das ferramentas disponíveis que normalmente é utilizado mais por engenheiros e matemáticos. A linguagem de programação é similar a alguns outros programas disponíveis como S, S-Plus ou mesmo o R. 
Há muitas ferramentas, conhecidas como "toolboxes" desenvolvidos gratuitamente por usuários e normalmente se fazem usos dessas ferramentas para uma adequada organização do mapa de visualização. Outros softwares estatísticos muito populares são Stata, SPSS, Minitab e SAS que provê vários recursos limitados de visualização.

O MatLab® apresenta uma visualização do estado da arte de sucesso. Em adicional a esses populares ambientes computacionais de visualização, existem outros que apresentam um ambiente de avaliação gratuito pela internet, como XGobi, XGvis, ORCA e SOM_PARK (MCLEOD, 2001). Por isso, ao explorar os recursos do aplicativo 'MatLab®', foi possível observar exemplos que exploram alguns dos caminhos possíveis para visualizar dados de alta dimensão, explorando o kit 'statistics toolbox' existente no 'MatLab®'.

O MatLab® foi escolhido, dentre outras vantagens, por sua ampla disponibilidade de bibliotecas, conhecidas como "ToolBox", as quais proporcionam uma estrutura favorável ao desenvolvimento de aplicações e protótipos desde os mais comuns até os mais complexos nas mais diversas áreas de conhecimento. Nesse trabalho, o recurso do MatLab® ficou por conta da "EconometricToolBox” e suas respectivas opções de visualizações gráficas.

Este software é destinado a fazer cálculos com matrizes (MATrix LABoratory), podendo funcionar como uma calculadora ou como uma linguagem de programação cientítica como Fortran, Pascal e C. O uso do MatLab® se torna mais simples por proporcionar uma escrita de expressões algébricas mais próxima do que estamos acostumados. Sendo assim, o MatLab® acaba sendo definido como um sistema interativo e uma linguagem de programação técnica e científica, com capacidade para fazer cálculos, programação e visualização gráfica. (MEDEIROS, 2011). Vale destacar aqui também que outro fator decisivo na escolha dessa ferramenta é que ele apresenta a licença de uso gratuita para estudantes da Universidade de São Paulo, tornando assim, viável sua instalação e operação.

\subsection{Desenvolvimento da visualização dos resultados por representação gráfica}

O MatLab® apresenta uma interface nativa de desenvolvimento de visualização de resultados conhecida como “GUIDE” (Graphical User interface Development Environment) que permite projetar a interface do usuário através da disponibilização de diversas ferramentas de configuração. Possui uma estrutura simplificada de programação e construção do ambiente. 
É considerada a parte mais importante do desenvolvimento, pois ela define as funções e comportamentos de cada componente. Usando o editor gráfico, o desenvolvedor pode construir sua tela num simples arrastar e soltar de botões, como botões de gráficos, painéis, campos de textos entre outros.

O "Guide" gera automaticamente um arquivo de programa contendo as funções de controle do MatLab® para realizar as operações de interfaces. Esses arquivos de códigos possuem instruções de inicialização baseadas em frameworks conhecidos como "CallBacks". Isso propicia as ações desejadas conforme a requisição da aplicação (JUNIOR, 2011).

A aplicação MatLab® possui uma seleção de caixas de diálogos básicas que podem ser criadas através de simples chamadas de funções. Por exemplo, se o desejo é de executar uma janela de boas vindas ao usuário, basta personalizar a função "msgbox". A "GUIDE" permite a produção de uma aparência consistente e com controles intuitivos.

É importante que o programador consiga proporcionar de forma previsível e compreensível para o usuário tudo o que a aplicação tem a oferecer, para que ele saiba o que esperar ao executar qualquer ação envolvida nos algoritmos.

Todo o ambiente de desenvolvimento é gerado na linguagem ".m” para as escritas de comandos e ".fig" para as interfaces de interação com o usuário, linguagens essa, que possuem código aberto, facilitando seu manuseio, alteração, melhorias e adaptações por qualquer outro profissional que sinta a necessidade de fazê-la, em especial, profissionais da área de economia e análise antitruste.

Através da figura abaixo, tirado de MatLab® (2012), é possível apreciar a interface de programação. 


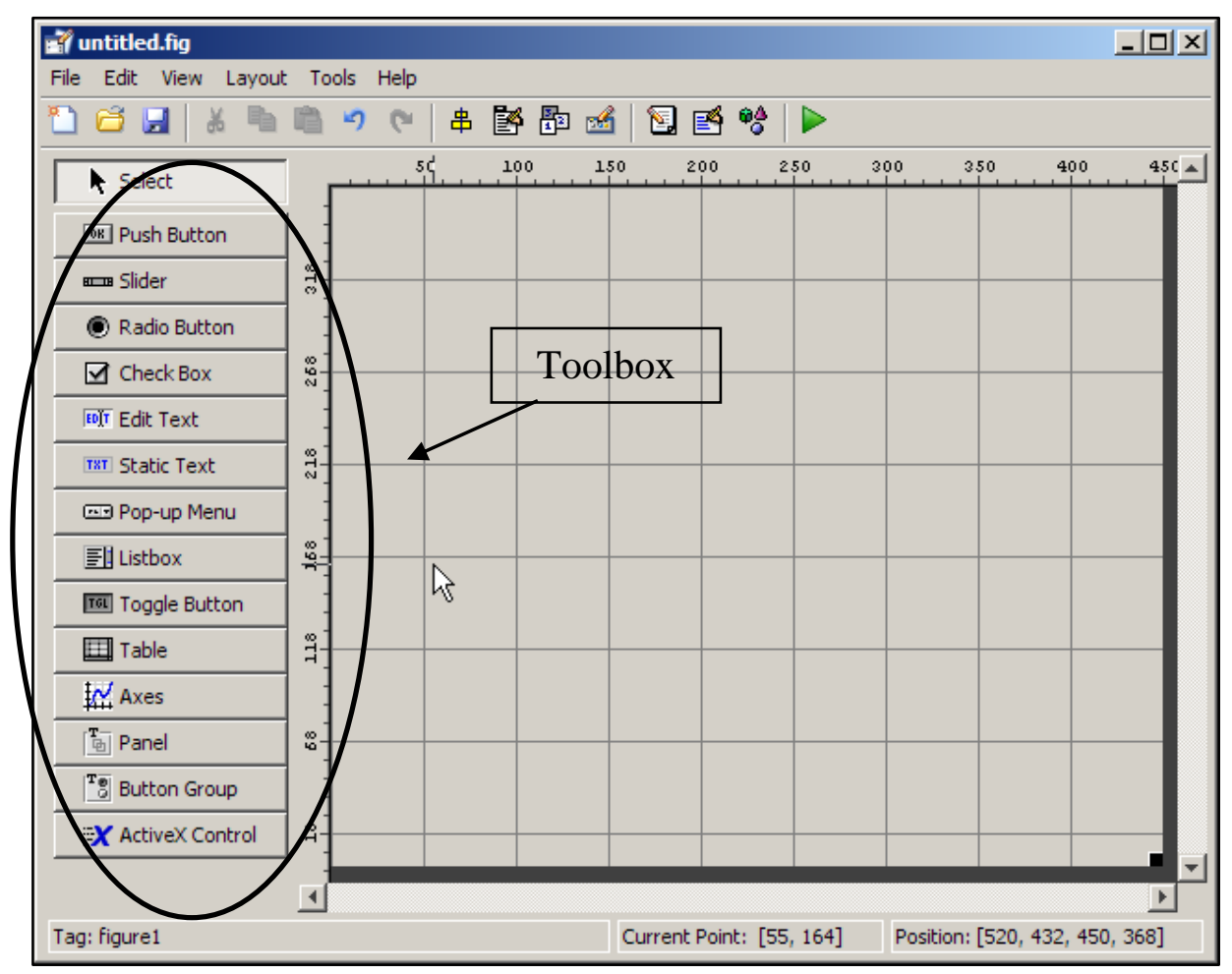

Figura 07 - Tela gráfica do GUIDE

Já na próxima figura, é possível observar a lógica de visualização empregada para a determinação do mercado relevante.


Figura 08 - Modelo de visualização. Adaptado de (NASCIMENTO et al., 2004 apud SOUZA, 2007) 
Assim, a implementação de um sistema de visualização para análise e estudo sobre o mercado relevante, a partir de resultados de testes de preços que estão armazenados em base de dados, permite a transformação dos dados abstratos em uma forma de exibição que facilite o seu entendimento.

\subsection{Desenvolvimento do sistema SITEMERE}

SITEMERE (sistema de teste de mercado relevante) é o nome dado ao sistema que aparecerá logo ao carregar o aplicativo executável (é executado mesmo em computadores que não tenham o programa Matlab instalado), dando as boas vindas ao usuário.



Figura 09 - Tela de bem vindo

Ao clicar no botão "OK" ou simplesmente fechar a janela, o sistema já vai imediatamente carregar a tela principal, como observado na figura 10. 


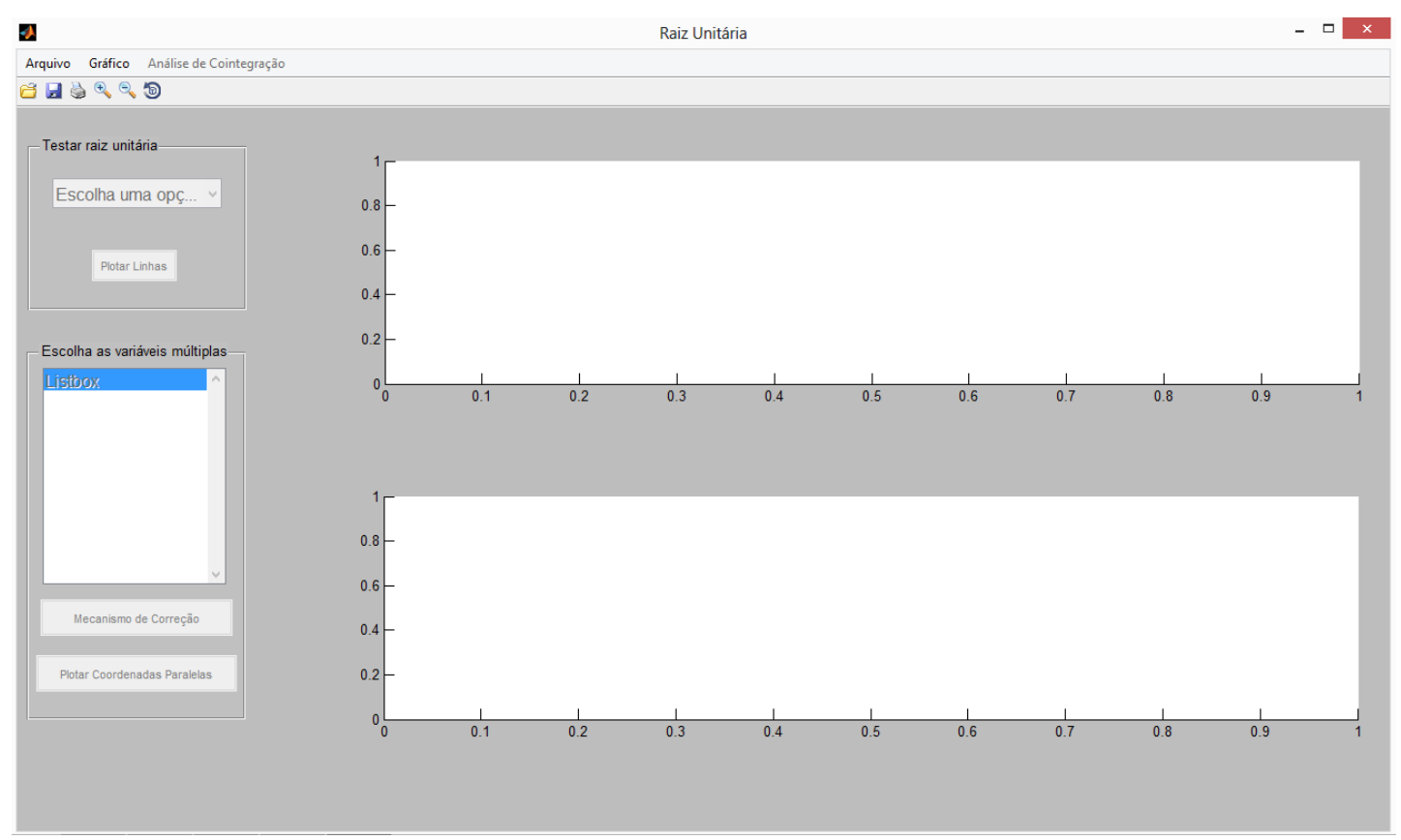

Figura 10 - Tela principal do programa

A escolha do MatLab® viabiliza a forma de como os dados brutos serão tratados. A primeira regra é compatibilizar os dados no formato padrão de leitura do aplicativo, ou seja, no formato com extensão (.mat). Esses dados brutos podem estar em vários formatos compatíveis, os mais recomendados são: tabelas Excel ou arquivo texto. Para criar esse padrão, a seguinte regra foi aplicada:

a) Através do MatLab, importar a base de dados. Como estamos tratando série de preços, haverá uma coluna específica para as datas, duas ou mais colunas com os valores (preços) e a linha (representada por um vetor) que contem o nome das variáveis;

b) Para que o sistema possa aceitar qualquer dado para análise, os nomes dos campos importados devem seguir um padrão rigoroso:

i. Para a coluna das datas, o campo recebe o nome de "DAATA";

ii. Para as colunas dos valores, desconsiderando o nome das variáveis, o nome dessa matriz será “completo";

iii. Para o vetor que representará a linha com o nome das variáveis, esse se chamará "legendas".

c) Após essas importações realizadas, o processo de leitura do conteúdo ocorrerá dentro da própria aplicação, conforme capítulo seguinte.

Para o processo de construção das visualizações, foram realizadas 2(duas) etapas: 
I. Construção da interface gráfica através de caixas interativas, recurso esse fornecido pelo "Guide" do MatLab;

II. Programação dos módulos (arquivos “.m”).

Todas as telas, gráficos, botões e outros controles foram manipulados a partir da tela principal mostrada na figura 07, utilizando recursos de habilitação de visualização e possibilidades de manuseio, recursos estes disponíveis no "property inspector", de cada controle inserido. A figura 11 mostra um exemplo de uma janela de propriedades de um controle. As propriedades que tratam essas manipulações de visualizações e permissões de edições são: "visible" e "enable".

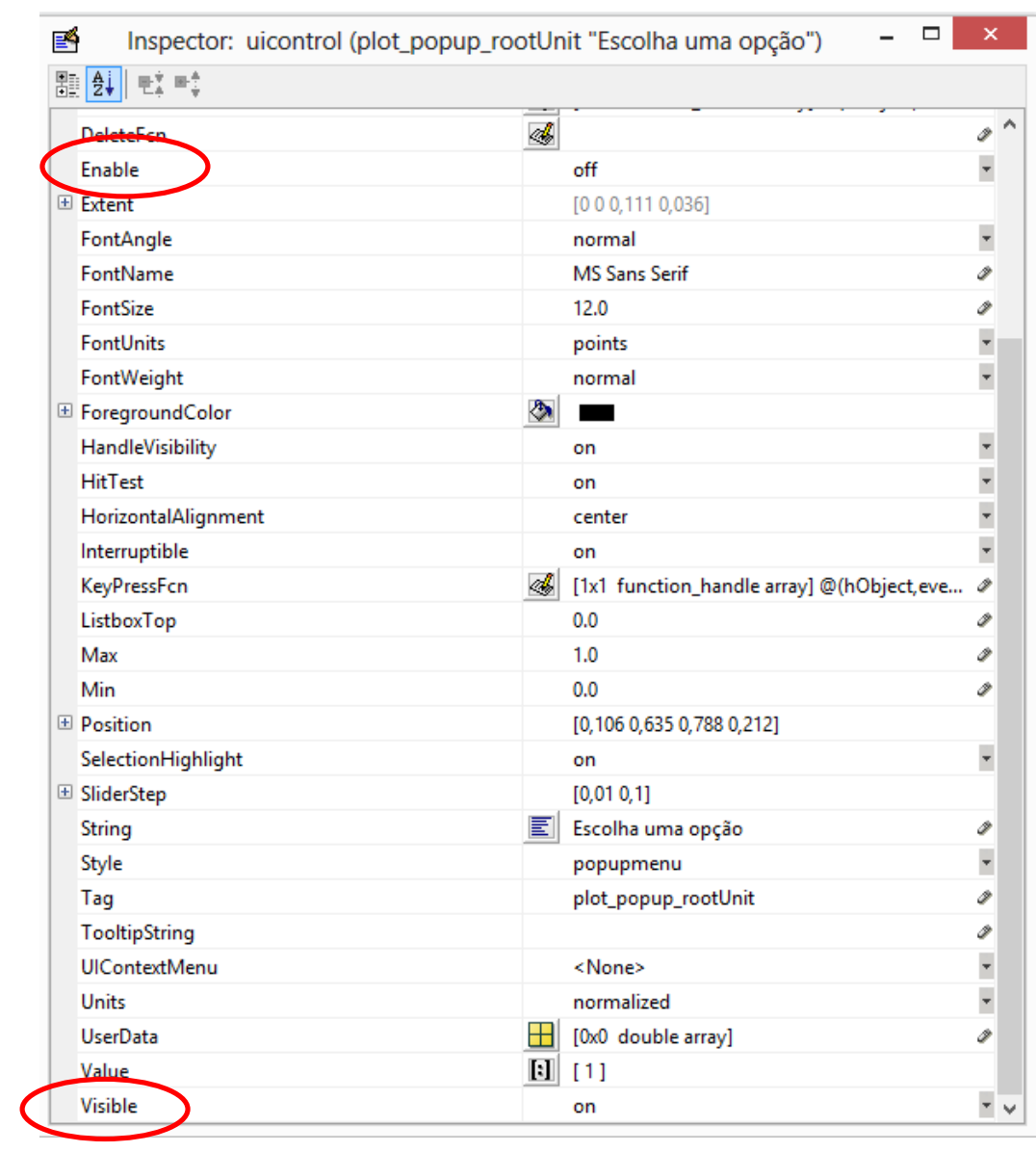

Figura 11 - Janela de propriedades dos controles

No total foram gerados 3 (três) telas:

a) A tela principal de "Bem Vindo";

b) A tela para geração dos gráficos de $\operatorname{logs}, 1^{\text {a }}$ diferença, visualização multivariada, coordenadas paralelas e mecanismo de correção de erro; 
c) A tela para visualização da análise de cointegração não linear.

No capítulo 5, as telas com seus resultados serão discutidas em maiores detalhes. 


\section{Capítulo 5}

\section{Resultados}

No item 4.3 foram descritos os processos de construção da aplicação. Agora, serão comentados os resultados obtidos de acordo com as escolhas do usuário. Para isso, é recomendado analisar o diagrama em blocos, abaixo, para entender a lógica da geração dos resultados. 


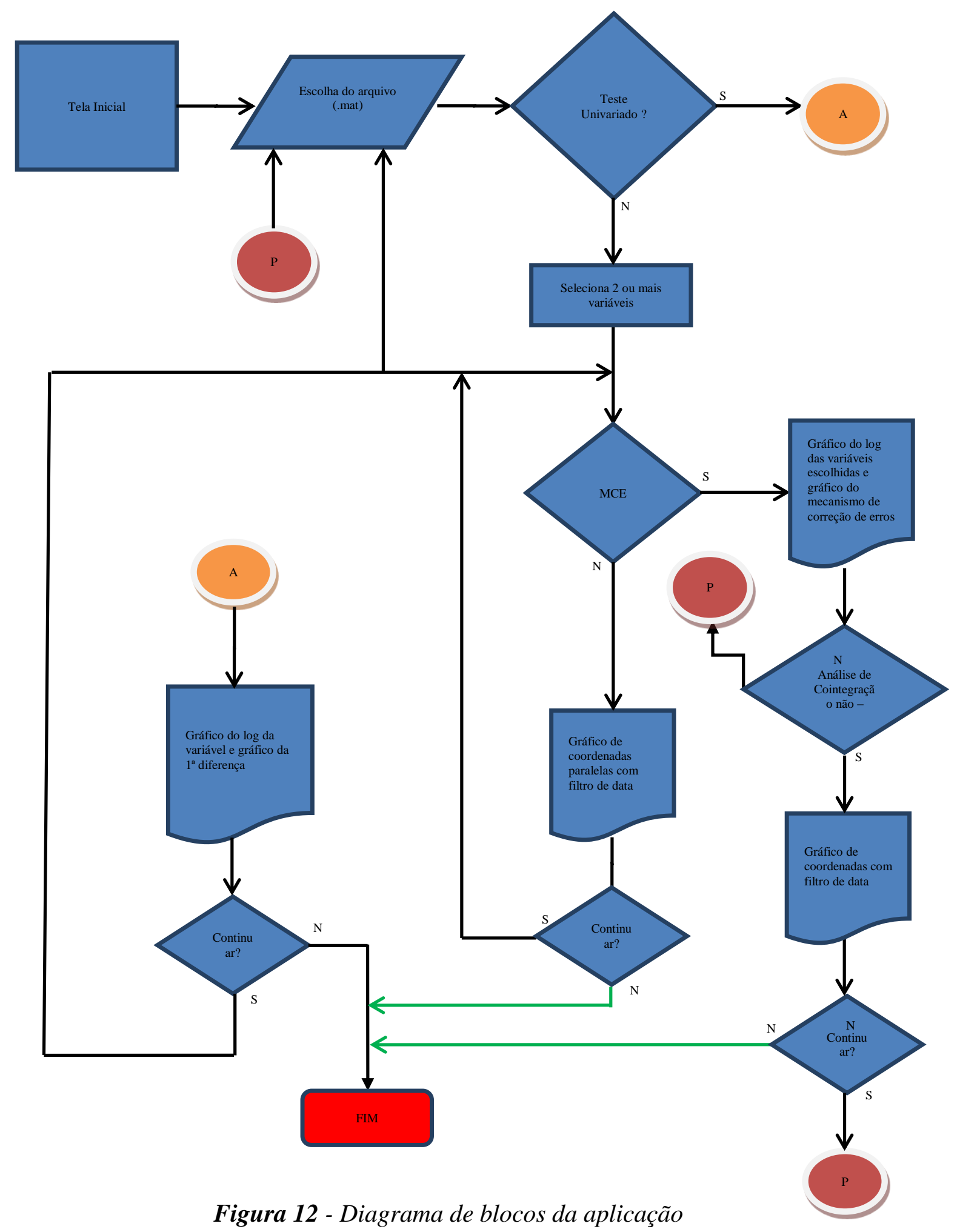

Como exemplo, escolheu-se a base de dados já formatada no padrão do MatLab®, com o nome "precMed_defla2_rev1.mat". Essa base contém a série de preços de medicamentos, compreendendo o período de Janeiro de 2002 a dezembro de 2009. Nessa base, existem 7 (sete) variáveis, representando série de preços de medicamentos. O programa 
foi desenvolvido para fazer análise de mercado com qualquer base de dados, desde que a importação dessa base esteja de acordo com o descrito no item 4.3.

Ao escolher a base de dados, selecionando a opção "abrir" do menu, a caixa de seleção no canto esquerdo superior habilita, para a geração do gráfico de log e da primeira diferença dessa variável selecionada. A caixa de seleção múltipla, logo abaixo, também habilita. O menu apresenta opção de abertura de arquivo, fechamento do programa e também o tipo de gráfico desejado para a visualização, além da opção de Análise de cointegração não linear (técnica de Kapetanios), como mostra a figura abaixo.

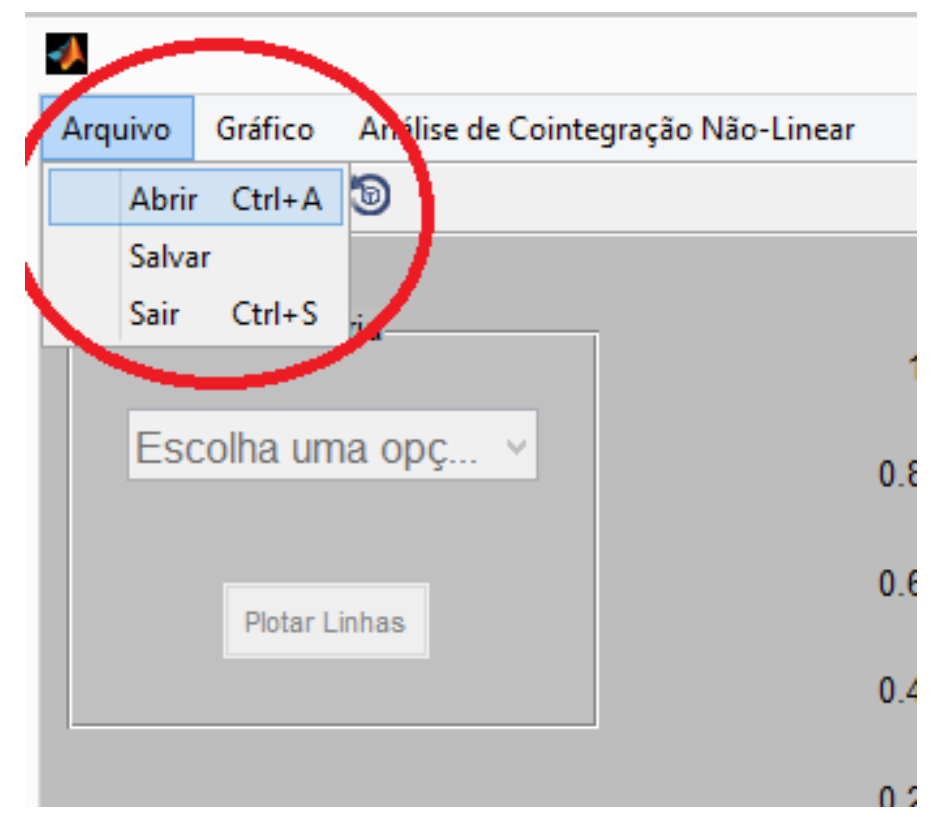

Figura 13 - Primeiro passo: Abertura da base de dados.

Na caixa múltipla, duas ou mais variáveis podem ser selecionadas para verificar tanto o mecanismo de correção de erro como também para gerar o gráfico de coordenadas paralelas. Para selecionar o grupo de variáveis, basta acionar a tecla "CTRL" e clicar nas variáveis desejadas. Se caso o desejo for por selecionar todas as variáveis, basta clicar na primeira variável e com a tecla "SHIFT" acionada, ir selecionando as demais variáveis com um clique em cima do nome delas ou simplesmente com a seta do teclado para baixo, descer a seleção.

O quadro dos gráficos é bastante interativo. Como mostra a figura 14, o layout da tela apresenta, ao lado direito, dois espaços de gráficos. Caso seja selecionado a verificação da raiz unitária, os dois gráficos mostrarão o $\log$ e a $1^{\text {a }}$ diferença daquela variável selecionada. Se caso a seleção for para múltiplas variáveis, os gráficos exibidos serão o log de todas as variáveis escolhidas juntas e o gráfico de mecanismo de correção de erro. Para isso, o botão 
com o nome "Mecanismo de Correção" deve ser acionado. Como exemplo, foi selecionado a base de dados "precMed_defla2_rev1.mat" e escolhido, para cálculo da raiz unitária, a variável "med7". No gráfico de log, é possível observar uma tendência de aumento de preço a partir de meados de julho de 2005. Já na observação da integração de primeira ordem, em outubro de 2002 e meados de novembro de 2006, ocorreram variações, o valor saiu um pouco do eixo de tendência a zero. Para os especialistas, juntamente com outros dados, podem chegar a alguma conclusão como, por exemplo, nesses períodos citados, ocorreram choques de preços, por alguma razão econômica específica. O importante é que o valor seguiu a tendência.

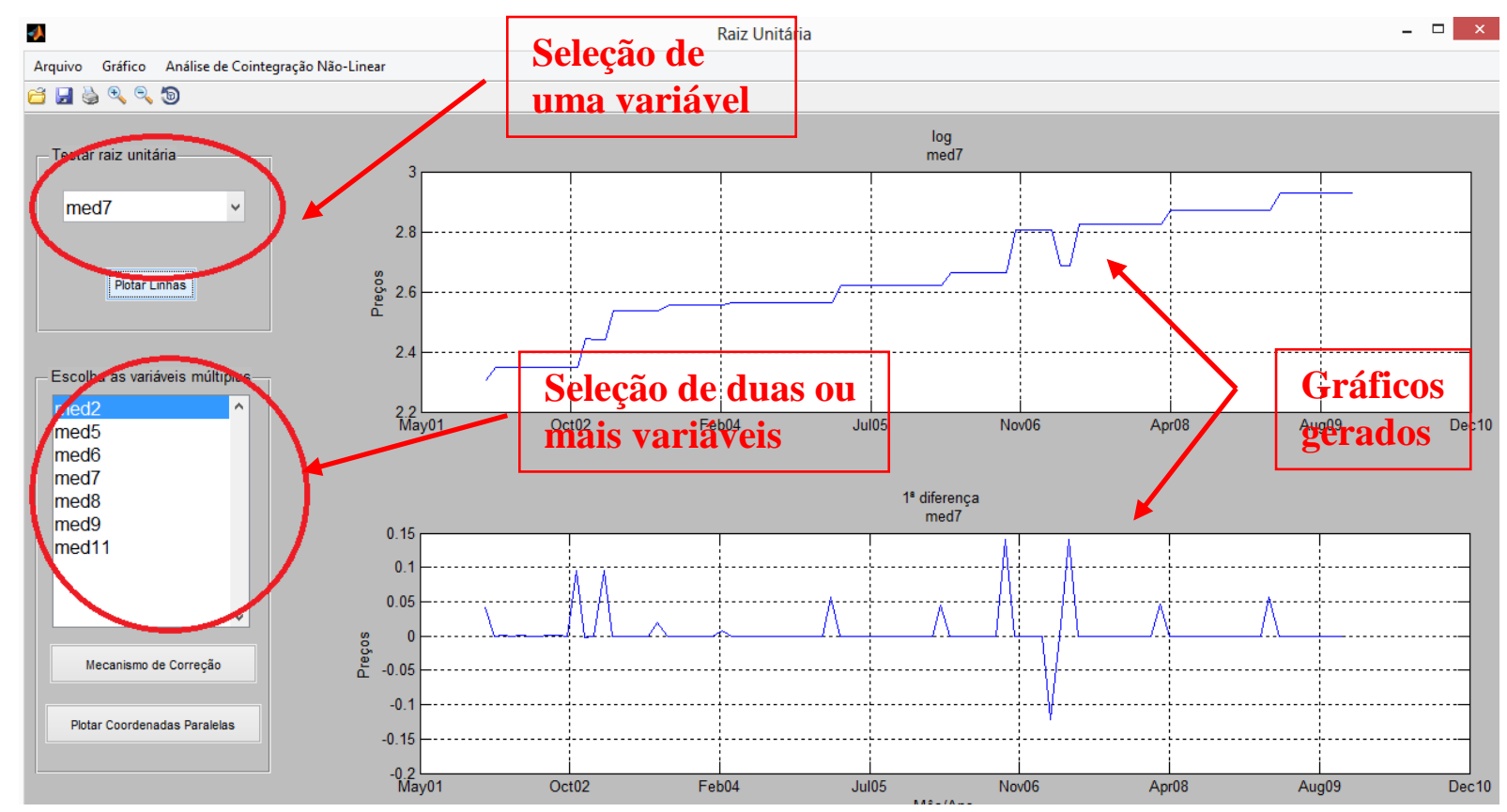

Figura 14 - Seleção de variável única para teste de raiz unitária

Na seleção de teste da raiz unitária, o programa também realiza os testes (DickeyFuller e Phillips-Perron). No caso da variável exemplo, "med7", no momento do acionamento do botão "Plotar Linhas", uma janela "pop-up" é exibida com os resultados dos testes de Dickey-Fuller e Phillips Perron. Os testes foram realizados com base em funções prontas do Matlab® disponíveis na versão 12: “adftest(y,'model','TS','lags',2)” e “pptest(y, 'model', 'TS', 'lags',2)” respectivamente. O “ $y$ ” é a variável unitária, com sua série de preço" analisada. A opção "lags" mostra o uso de 2 Lags, um valor considerado comum para testes de preços dessa natureza.

Quando o resultado dos testes aplicados é igual a 0 (zero), significa que não é rejeitada a hipótese nula de cointegração, ou seja, é integrada de primeira ordem, ou, é uma raiz 
unitária. Caso o resultado obtido for igual a 1(um), então a hipótese nula é rejeitada. A tela do resultado é mostrada abaixo:

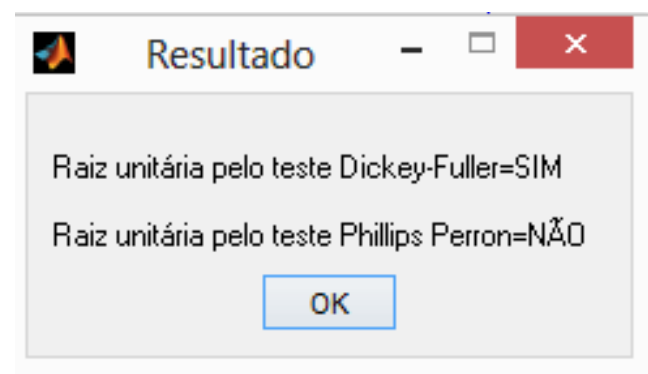

Figura 15 - Tela de demonstração dos resultados de raiz unitária

A fim de reforçar a comparação dos testes, uma tabela com os resultados aplicados em todas as variáveis de série de preços de medicamentos foi construída.

\begin{tabular}{|c|c|c|c|c|}
\hline VARIÁVEL & LAG & TENDÊNCIA & $\begin{array}{l}\text { TESTE DICKEY- } \\
\text { FULLER }\end{array}$ & $\begin{array}{l}\text { TESTE PHILLIPS- } \\
\text { PERRON }\end{array}$ \\
\hline Med2 & 2 & Não & Não rejeita H0 & Não rejeita $\mathrm{HO}$ \\
\hline Med5 & 2 & Não & Não rejeita $\mathrm{HO}$ & Rejeita $\mathrm{HO}$ \\
\hline Med6 & 2 & Não & Não rejeita $\mathrm{HO}$ & Não rejeita $\mathrm{HO}$ \\
\hline Med7 & 2 & Não & Não rejeita HO & Rejeita HO \\
\hline Med8 & 2 & Não & Não rejeita $\mathrm{HO}$ & Rejeita $\mathrm{HO}$ \\
\hline Med9 & 2 & Não & Não rejeita H0 & Rejeita H0 \\
\hline Med11 & 2 & Sim & Rejeita $\mathrm{HO}$ & Rejeita $\mathrm{HO}$ \\
\hline
\end{tabular}

Tabela 03 - Comparativo de testes de raiz unitária em cada variável

Já na seleção de múltiplas variáveis, escolheu-se, como exemplo, as variáveis med2, med5 e med7. Acionando o botão "Mecanismo de Correção", geraram-se 2 gráficos. No primeiro, acima, é possível observar o log das 3 variáveis juntas, analisando o comportando de ambas na linha de variação dos preços por tempo. Já no quadro de baixo, é possível observar o mecanismo de correção de erro. Nesse gráfico, foram traçados duas linhas limites, uma na cor preta, que representa o limite da média mais duas vezes o desvio padrão, uma linha vermelha, que representa o limite da média - 2X o desvio padrão e uma linha na cor verde, representando o limiar zero, valor de tendência. Já a linha azul, demonstra o resultado do teste, que pode implicar na existência ou não de cointegração (isso é considerado como testes iniciais).

Também na janela de menus, têm-se as opções de manipulação das imagens geradas, podendo, por exemplo, rotacioná-la ou mesmo aplicar uma "lente de aumento", ao qual o usuário seleciona um trecho da área do gráfico que deseja aplicar essa lente.

A fórmula no MatLab® para a criação do mecanismo de correção de erros segue os passos abaixo: 


\section{Passo 01: Verificando quantidade de amostras:}

cont=length $(\mathrm{Y})$; (Y representa a coluna 1 da matriz gerada com as variáveis selecionadas, nesse exemplo, representando a variável “med2");

\section{Passo 02: Criando a matriz de "ones":}

$\mathrm{X} 2=[$ ones $($ cont, 1$), \mathrm{X} 2]$;

O X2 são as demais variáveis da matriz construída, nesse exemplo, representariam o "med5" e o "med7"

\section{Passo 03: $O$ comando abaixo gera a coluna de regressão:}

$[\mathrm{B}, \mathrm{BINT}, \mathrm{R}, \mathrm{RINT}, \mathrm{STATS}]=\operatorname{regress}(\mathrm{Y}, \mathrm{X} 2)$;

\section{Passo 04: calculando mecanismo de correção de erro:}

michapeutmenos $1=\operatorname{lagmatrix}(\mathrm{R},-1)$;

Através da função "lagmatriz" dando a defasagem de 1, geramos o $\hat{\mu}$.

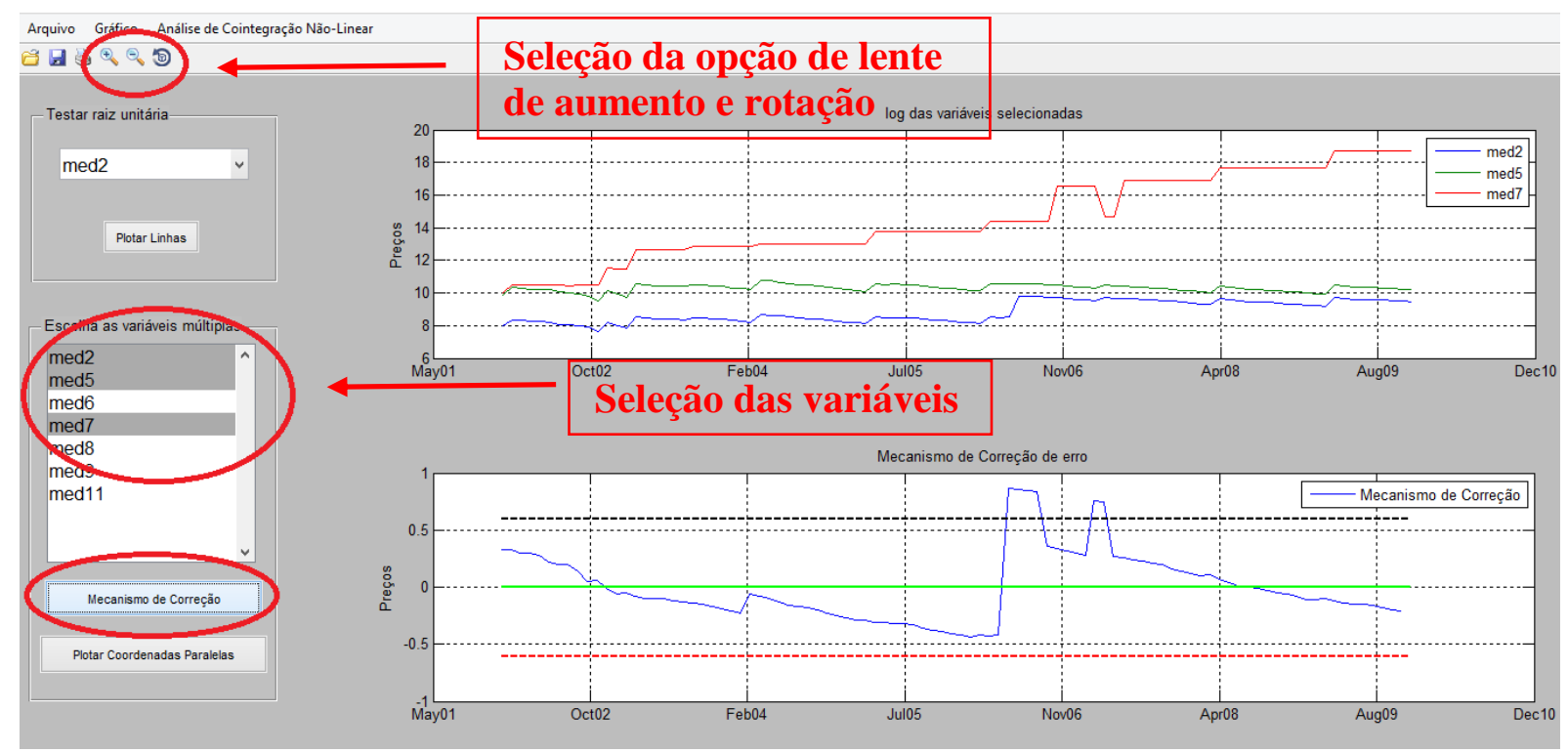

Figura 16 - Aplicação do mecanismo de correção de erro

Caso seja acionado o botão "Plotar Coordenadas Paralelas", o layout da tela sofrerá uma pequena alteração, sendo exibido um gráfico maior em substituição ao espaço dos outros dois gráficos. Ao gerar esse gráfico, uma interação com o usuário é criada, propondo a ele uma marcação no gráfico do ponto mais crítico que tenha chamado a sua atenção. Logo à esquerda, habilitam-se os controles de seleção para fazer um filtro optando por somente anual ou somente mensal. Caso a base de dados se ausente de um desses intervalos (ano ou mês), simplesmente não irá gerar a linha respectiva, mas isso NÃO é considerado um erro, apenas uma ausência de período. No ano, assim como no mês, pode-se selecionar mais de uma opção. 
Para ativar esses filtros, basta acionar o botão "Ative o filtro" que se localiza acima do quadro de seleção do ano ou do mês.



Figura 17 - Tela de coordenadas paralelas

Na figura 17 acima, de coordenadas paralelas, temos:

a) A representação do ponto crítico, onde se chamou a atenção do usuário e ele então realizou essa marcação;

b) Os filtros por ano e por mês. Para trabalhar com eles, basta clicar no botão "Ative o filtro" que se encontra acima de cada caixa de seleção;

c) O botão "Voltar" permite ao usuário retornar à tela anterior, onde ele poderá fazer uma nova seleção de raiz unitária ou mecanismo de correção de erros;

d) Através da opção no menu "Análise de cointegração não linear" é possível comprovar a suspeita de que a hipótese nula de não-cointegração poderá ser rejeitada. Sendo assim, vale a pena testar a análise de cointegração. Caso contrário, pode não valer a pena porque se o resultado da aplicação do mecanismo de correção de erro ficar muito fora da tendência a zero, a hipótese-nula NÃO será rejeitada. Tanto que no gráfico do mecanismo, existem duas linhas, uma na cor preta e outra na cor vermelha, representando os limites da média para +- ( 2 x desvio padrão). 
Com o interesse da análise de cointegração, ao clicar nessa opção do menu, a tela mostrada na figura 18 aparecerá, com as seguintes descrições:

a) De início, será solicitado ao usuário a escolha da base de dados. Ele tem a flexibilidade de selecionar outra base de dados, caso seja de seu interesse;

b) A partir da seleção da base de dados desejada, o quadro de seleção de múltiplas variáveis é carregado, dando a permissão de selecionar todas ou algumas variáveis para a análise;

c) Também o usuário tem a opção de escolher a quantidade de "lags";

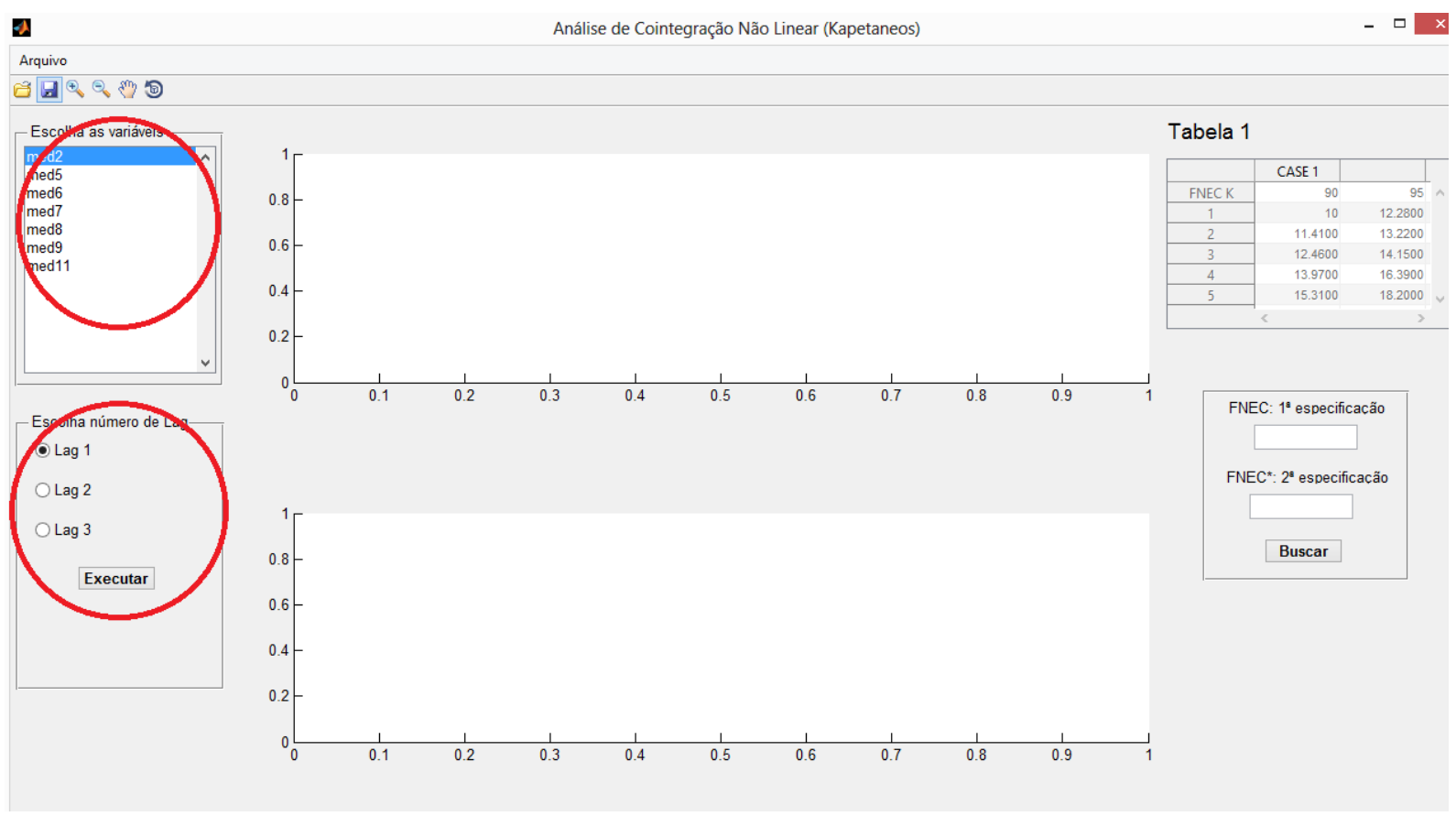

Figura 18 - Tela de análise de cointegração não linear

Ao escolher a quantidade de lags e clicar no botão "Executar", a seguinte tela será gerada: 


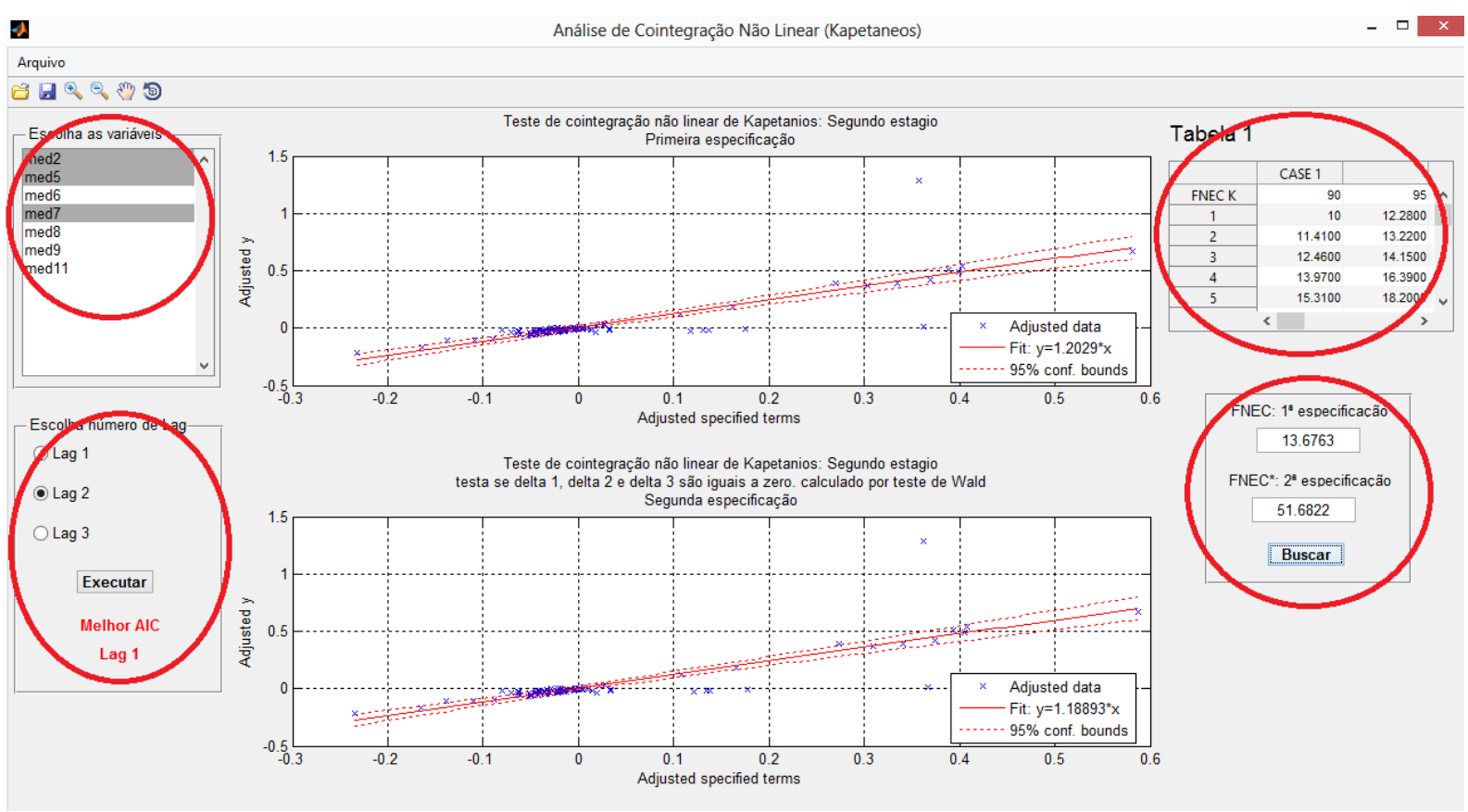

Figura 19 - Tela do teste de coitengração com os gráficos de dados ajustados

a) Usamos como exemplo, o mesmo grupo de variáveis: "med2", "med5" e "med7". Mas o usuário pode selecionar todas as variáveis, o que é mais comumente praticado;

b) Ao clicar no botão "Executar", com o "Lag2" selecionado, gerou-se então os gráficos construídos a partir da regressão do segundo estágio. Um ponto interessante a ser observado é que, em linha vermelha, sugere-se qual o melhor modelo de Lag a ser aplicado. Esse cálculo é feito a partir da melhor análise AIC/BIC, na primeira especificação da segunda regressão do segundo estágio (variável “md12"). A partir disso, é feito então uma comparação entre os AIC's e os BIC's entre os Lags 1, 2 e 3. O menor AIC/BIC representa um melhor modelo. Se não coincidir os menores AIC's e BIC's no mesmo número de Lag, então é priorizado o modelo que apresenta o menor AIC. Os gráficos representam a primeira especificação e a segunda especificação da regressão do segundo estágio (mdl2 e mdl2_2), como descrito em 2.4;

c) O valor do "teste F" pesquisado surgirá na caixa de texto. Ao acionar o botão "Buscar", a tabela 1, com os valores padrões FNEC e F*NEC, ao lado direito da janela, habilitará. Esse teste vem da regressão do segundo estágio do procedimento proposto por Kapetanios et al (2006), assim como os valores da tabela 1. As fórmulas aplicadas são descritas no item 2.4. Os comandos do 
MatLab®, para a construção da análise de cointegração, está toda descrita no apêndice “A”. Também, ao acionar o botão buscar, surgirá 2(duas) janelas de mensagens, apresentando uma mensagem positiva ou negativa, quanto à ocorrência de cointegração não linear, como mostra a figura 20:

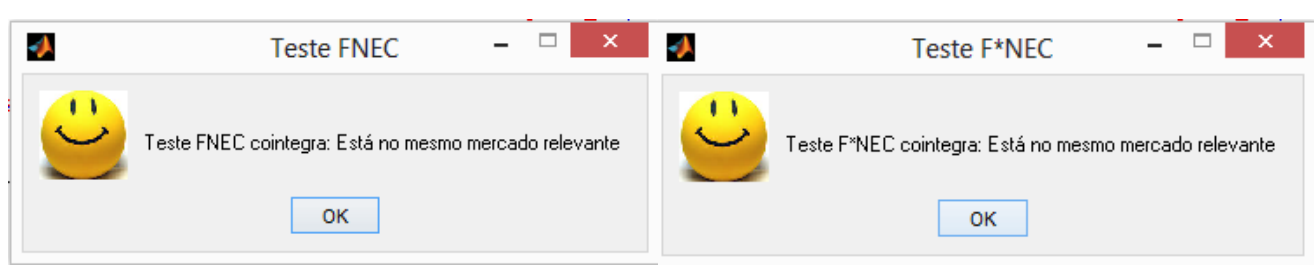

Figura 20 - Telas com os resultados de FNEC e $F^{*} N E C$

d) Os gráficos representam os dados ajustados, em uma matriz de "0" e "1", de acordo com o número de variáveis explicativas, tanto na primeira especificação quanto na segunda especificação da regressão do segundo estágio.

Para completar os resultados de visualização, uma janela com os dois valores encontrados de resíduos das duas especificações do segundo estágio estimadas, é gerada em formato "pop-up", contribuindo ainda mais para facilitar a interpretação do usuário, como pode ser visto na figura 21, abaixo:

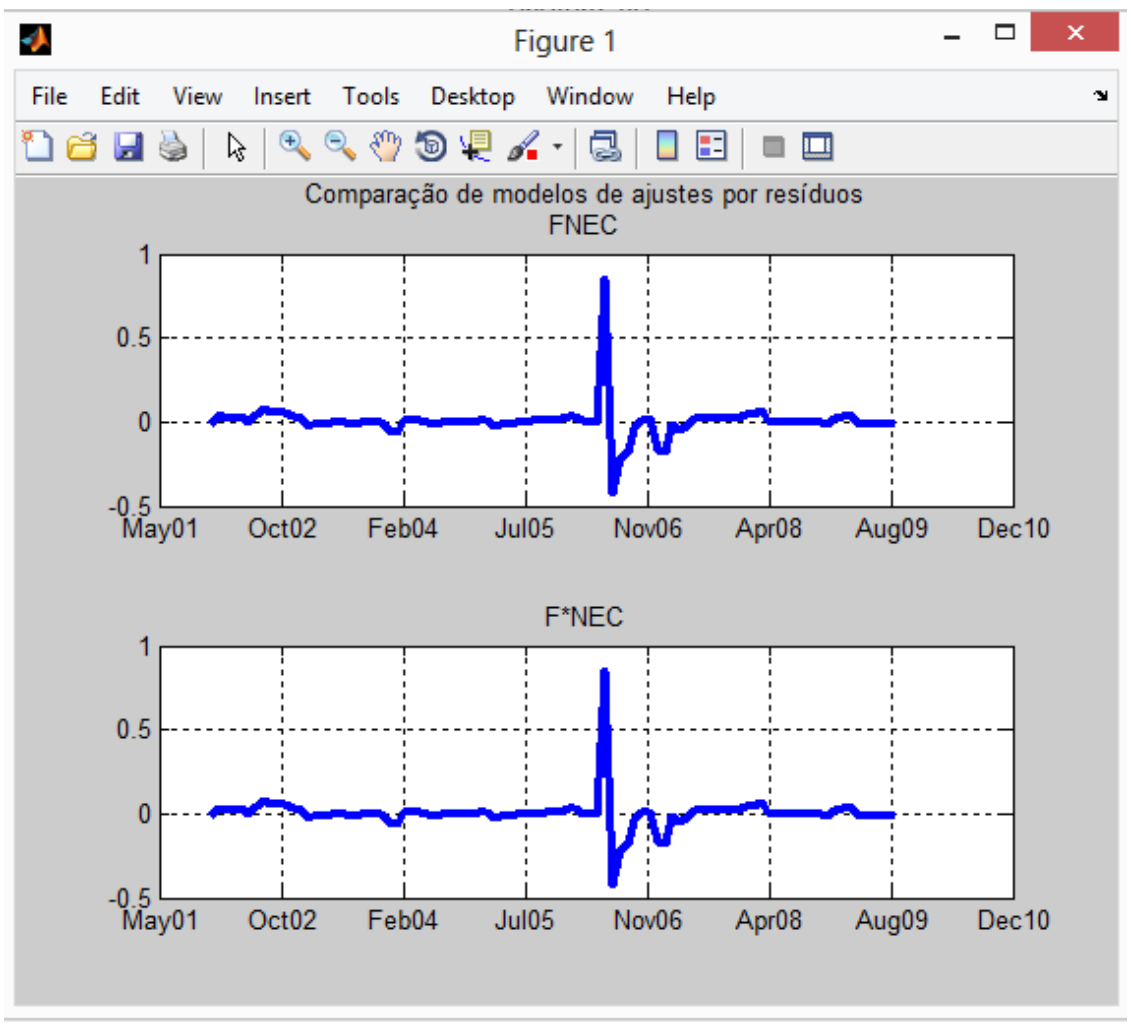

Figura 21 - Informações dos resíduos 


\section{Capítulo 6}

\section{Considerações Finais}

O objetivo deste estudo foi aplicar uma técnica de visualização de informação conjugada com uma aplicação de teste de preços, análise de cointegração não linear proposta por Kapetanios et al. (2006), para determinação de mercado relevante, proporcionando a junção de um trabalho multidisciplinar entre as áreas de sistema de informação e a subárea da economia de estudos antitruste e de defesa da concorrência. Este estudo foi motivado, em parte, pela realização de uma revisão sistemática que revelou haver pequena intersecção entre estas áreas, sendo o elemento comum à aplicação de técnicas de preços não lineares no mercado financeiro. Esta ausência de trabalhos em conjunto revelou-se um campo aberto para aplicações multidisciplinares em que a visualização da informação pode contribuir para a melhor disseminação da informação junto a um grupo heterogêneo de profissionais envolvidos em apresentações realizadas por economistas, incluindo advogados e profissionais de gestão das áreas pública e privadas.

No que se refere à área antitruste, o trabalho é uma contribuição ao usar uma técnica de preço não linear, cointegração linear, que é considerada mais robusta para séries de tempo mais curtas do que as lineares. Além disso, as técnicas de preços exigem menos informações do que as demais técnicas alternativas, que não de preços, que pressupõem estimativas de demanda e são bastante custosas em termos da quantidade de informação necessária para sua condução. Neste sentido a disponibilização de um instrumento analítico visual e estatístico adicional aplicando análise de cointegração não linear, poupador de recursos, pode auxiliar as análises antitrustes em que as ações são interdisciplinares. O uso da técnica de preços como determinação de mercado relevante não é permitido em todas as jurisdições, mas no Brasil é uma prática aceita.

Sendo assim, abriu-se espaço para o desenvolvimento de uma ferramenta visual para facilitar a apresentação dos resultados dos testes de preços, contribuindo sobremaneira como um instrumento adicional para as análises desta natureza. A ferramenta de visualização com o desenvolvimento interativo de uma interface de usuário, bem como as estimativas econométricas, foi desenvolvida no ambiente do aplicativo MatLab®. A ferramenta possibilitou a utilização em equipamentos de computação sem grandes exigências de 
hardware e software, neste último caso pela constituição de um programa executável. O usuário é capaz de "navegar" na cena apresentada, possibilitando uma visão genérica dos dados e, ao mesmo tempo, uma observação mais detalhada dos dados mais relevantes à consulta. Essa ferramenta desenvolveu-se numa linguagem aberta, através da interface "guide" que propicia a qualquer desenvolvedor ou usuário, adaptar, alterar ou excluir trechos de códigos de acordo com suas necessidades.

Considerando a utilidade desta ferramenta no auxílio aos profissionais interessados ligados diretamente a área de economia, vislumbrou-se a criação de recursos visando a oferecer ao usuário a opção de escolha de 2 (dois) ou mais produtos, gerando assim metáforas para visualização da informação.

Um destaque na contribuição desse trabalho também ficou por conta da revisão sistemática elaborada, observando que não existem trabalhos correlatos ligados diretamente à série de preços para determinação de mercado relevante de bem. Uma revisão bibliográfica também realizada no período de agosto a dezembro de 2013, nos principais sites como google acadêmico, IEEE Iexplore entre outros, foi possível observar diversos trabalhos interdisciplinares que utilizam a ferramenta MatLab® como interface de visualização, mas não foi possível encontrar um trabalho específico que utilizasse essa ferramenta diretamente ligada a uma forma de determinação de mercado relevante. 


\section{Capítulo 7 \\ Referências}

\subsection{Referências bibliográficas}

ABOKHALAF, N.; MARTINS, C.; PINHO, P.; PEREIRA, J.F.R. Utilização do Matlab® como Ferramenta de Desenvolvimento e de Visualização Gráfica dum Programa de Análise de Antenas pelo Método de FDTD. Revista do Detua, Vol. 3, Nº 5, Janeiro 2002.

AKAIKE, H. A new look at the statistical model identification, IEEE Transactions on Automatic Control 19 (6): 716-723, 1974.

AMENTA, N.; BERN, M.; KAMVYSSELIS, M. A new Voronoi-based surface reconstruction algorithm.Computer Graphics, v. 32, n. Annual Conference Series, p. 415\{421, 1998.

BAKER, JB; BRESNAHAN, T.F. Economic Evidence in Antitrust: Defining Markets and Measuring Market Power. Handbook of Antitrust Economics. Edited by P. Buccirossi. MIT Press, 2008.

BERTI, C. B. VRVis: Ferramenta de Realidade Virtual para Visualização de Informações. 2004. 100 f. Dissertação (Mestrado em Ciência da Computação) - Centro Universitário Eurípides de Marília, Fundação de Ensino Eurípides Soares da Rocha, Marília, 2004.

BIOLCHINI, J.; MIAN, P.; NATALI, A. and TRAVASSOS, G. Technical Report to Systematic review in software engineering. System Engineering and Computer Science Department. RJ, 2005. 
BOX, G. E. P., JENKINS, G. M.; REINSEL, G. C. Time Series Analysis: Forecasting and Control. 3rd ed. Upper Saddle River, NJ: Prentice-Hall, 1994.

COAN, A.L.; Nishijima, M.; Nunes, F. L. S. Computational Techniques and price tests for determining relevant markets: a systematic review. Revista AMDE (Associação mineira de direito e economia). ISSN 2175-5590. USP, 2013.

COE, P.F.; KRAUSE, D. An analysis of price-based tests of antitrust market delineation. Journal of Competition Law \& Economics, 4(4), 983-1007.Oxford University, 2008.

COMMERCE commission: merges and acquisitions guidelines. jannuary, 2004.

DAVIDSON, J.; MONTICINI, A. Tests for cointegration with structural breaks based on subsamples. UK, Italy, 2010. 1

DICKEY, D. A.; FULLER, W. A. "Distribution of the Estimators for Autoregressive Time Series with a Unit Root", Journal of American Statistical Association, vol. 74, No 366, PP. 427-431, JUNE 1979.

DICKEY, D. A.; FULLER, W. A. "Likelihood Ratio Statistics for Autoregressive Time Series with a Unit Root”, Econometrica, vol. 49, No4, JULY, 1981.

DOORNIK, J. A.; O'BRIEN, R. J. Numerically stable cointegration analysis. UK, 2002.

EASTON, G.S.; MCCULLOCH, R.E. A multivariate generalization of quantile-quantile plots, Journal ofthe American Statistical Association 85, 376-386, 1990.

ENDERS, Walter. Applied econometric time series. United States: John Wiley \& Sons, $517 \mathrm{p}, 2010$. 
ENGLE, Robert F.; GRANGER, C. W. J. Long-run economic relationship: readings in cointegration. New York: Oxford University Press. 301p. (Advanced Texts in Econometrics), 1991.

FORNI, M. "Using Stationary Tests in Antitrust Definition". American Law and Economics Review, Oxford, v.6, n2,pp 441-464, 2004.

FELIZARDO, K. R.; MARTINS, R. M. Engenharia de Software Experimental: uma Revisão Sistemática. USP, 2011

FULLER, Wayne A. Likelihood ratio statistics for autoregressive time series with a unit root. Econometrica, Chicago, v.49, n. 4, p.1057-1072, Jul. 1981.

GONÇALVES, V. M.; NUNES, F. L. S.; DELAMARO, M. E. Avaliação de Funções de Similaridade em Sistemas de CBIR: uma Revisão Sistemática. USP, 2011.

GONÇALVES, R. N. L. Estudo do impacto da introdução dos veículos elétricos nos preços de Mercado e nos diagramas de carga. Faculdade de engenharia da Universidade do Porto. Dissertação de mestrado, 2012.

HAMILTON, James D., Time Series Analysis, chap. 17, 18 e 19, Princeton University Press, New Jersey, 1994.

HENDRY, D., Dynamics Econometrics , Oxford University Press, 1995.

HORIZONTAL Merger guidelines.u.s. department of justice and the federal trade commission. issued: august 19, 2010.

HÖRNER, J.; Samuelson, L. Managing Strategic Buyers. US, 2011. 
JOHANSEN, S. Likelihood-based inference in cointegrated vector auto-regressive models. New York: Oxford University Press. 267 p. (Advanced Texts in Econometrics), 1995.

JOHANSEN, S.; JUSELIUS, K. Maximum likelihood estimation and inference on cointegration with applications to the demand for money.Oxford Bulletin of Economics and Statistics, v. 52, n. 2, p. 169-210, 1990.

JOHANSEN, S. Estimation and hypothesis testing of cointegration vectors in Gaussian vector autoregressive models. Econometrica, 59(6), 1991.

JOHANSEN, S. Identifying restrictions of linear equations with applications to simultaneous equations and cointegration. Journal of Econometrics, 69.(2), 1995a.

JOHANSEN, S. Likelihood-Based Cointegrated Vector Auto-Regressive Models. Advanced Texts in Economics. Oxford University Press, New York, 1995 b.

JOHANSEN, S.; JUSELIUS, K. Maximum likelihood estimation and inference on cointegration. Oxford Bulletin of Economics and Statistics, 52(3),1990.

KAPETANIOS, G.; SHIN, Y.; SNELL, A. Testing for a unit root in the nonlinear STAR framework. Journal of Econometrics 112, 359-379. UK, 2003.

KAPETANIOS, G.; SHIN, Y.; SNELL A. Testing for cointegration in nonlinear smooth transition error correction models. Econometric Teory, 22.279-303, USA, 2006.

KASPARIS, I. The Bierens test for certain nonstationary models, Journal of Econometrics, Volume 158, Issue 2, Pages 221-230, October 2010.

KITCHENHAM, B. Procedures for performing systematic reviews Technical Report TR/SE0401, Keele University and NICTA, 2004 
LOADER, C. Local Regression and Likelihood, Springer, New York, 1999.

MARGARIDO, M. A.; Teste de co-integração de Johansen utilizando o SAS. Agric. São Paulo, São Paulo, v. 51, n. 1, p. 87-101, jan./jun. 2004.

MARGARIDO, M. A.; ANEFALOS, L.C. Testes de raiz unitária e o software SAS. AGric. São Paulo, 46.19-45.SP, 1999.

MATLAB®. Creating Graphical User Interfaces. R2012b. The MathWorks, Inc. Natick, MA, 2012.

MCLEOD, A.I.; PROVOST, S.B. Multivariate Data Visualization, article, January 29, 2001.

MATLAB®. Creating Graphical User Interfaces. R2012b. The MathWorks, Inc. Natick, MA, 2012.

MEDEIROS, A. G. Aplicação do guide do matlab na redução de cônicas. Universidade Federal Rural, UFERSA. TCC.RN, 2011.

MERGES and acquisitions guidelines. Commerce Commission, New Zealand.

MINISTÉRIO da Fazenda. Portaria Conjunta SEAE/SDE Nº 50, de $1^{\circ}$ de Agosto de 2001.

NISHIJIMA, M. Fluxos de comércio no Brasil e seus determinantes básicos - Uma análise de co-integração. Dissertação de mestrado. Universidade estadual de campinas. Instituto de economia, 1998. 
NETO, R. M. Visualização tridimensional de programas orientados a objeto. Dissertação (Mestrado em Ciência da Computação) - PPGCC - Programa de Pós-graduação em Ciência da Computação, Fundação de Ensino Eurípides Soares da Rocha, Marília, 2006.

NG, S.; PERRON, P. Unit Root Tests in ARMA Models With Data Dependent Methods for Selection of the Truncation Lag. Journal of the American Statistical Association 90, 268-281, 1995.

OZKAN, O.; AKTAS, M.; KUYUK, H. S.; BAYRAKTAROGLU, S.; "Energy Production and Economic Growth: A Causality Analysis for Turkey Based on Computer. Ninth International Conference on, PP.669-674, 12-14 DEC. 2010. 1

ÖSTERMARK, R. Multivariate cointegration analysis of the Finnish-Japanese stock markets.Finland, 2001.1

PEREIRA, P. L. V., Cointegração e suas Representações: Uma Resenha. Revista de Econometria, vol. 11, nº 2, pp. 185-216, Rio de Janeiro, novembro 1991.

PHILLIPS, P.C.B.; PERRON, P. Testing For A Unit Root In Time Series Regression, Biometrika, 75, 335-346, 1988.

PITELLI, M. M. Testes de preços para a determinação do mercado relevante geográfico e de produto: uma aplicação empírica ao mercado brasileiro de compra de bovinos. SP, 2008.

RIBEIRO, I.; SILVA, L.; FARIAS, C.; FILHO, E. S.; JUNIOR, E.B. Desenvolvimento de ferramenta computacional para configuração de sistema de ensaio ultrassônico, aquisição e processamento de sinais. GPEND (Grupo de ensaio não destrutivos) - IFBA, 2013.

SALGADO, L. H. U.S. Defesa da Concorrência no Brasil em momento de decisão. SP, 2011. 
SANTOS, S. H. O. VRVis Manager - Uma ferramenta para visualização de grandes volumes de dados usando realidade virtual. 2010. 117 f. Dissertação (Mestrado em Ciência da Computação) - Centro Universitário Eurípides de Marília, Fundação de Ensino Eurípides Soares da Rocha, Marília, 2010.

SCHWARZ, G. E. Estimating the dimension of a model. Annals of Statistics 6 (2): 461-464, 1978.

SOUZA, C. B.; ANDREÃO, R. V.; SEGATTO, M. V. Processamento de sinais de ECG para geração automática de alarmes. VI Workshop de informática médica. Universidade Federal do Espírito Santo, 2006.

SOUZA, A. S. Avaliação de técnicas de visualização de informações na Web: Estudo de caso - Mapa do site do UNIRITTER. Centro Universitário Ritter dos Reis. Porto Alegre, 2007.

TEIXEIRA, H. T. Desenvolvimento de um ambiente de controle e monitoramento em tempo real usando o MatLab e a placa de aquisição NUDAQ PCI-9112. Universidade Federal do Espírito Santo. Centro Tecnológico. Departamento de engenharia elétrica. Projeto de graduação, 2008.

U.S. Department of Justice and the Federal Trade Commission. Horizontal Merger Guidelines. Issued: August 19, 2010.

WEGMAN, E.J. Hyperdimensional data analysis using parallel coordinates, Journal of the AmericanStatistical Association 85, 664-675 (1990).

WEGMAN, E.J.; CARR, D.B. Statistical graphics and visualization. In Handbook of Statistics 9,Computational Statistics C.R. Rao, ed. North Holland, New York, 857-958, 1993. 
WERDEN, G.J.; FROEB, L.M. "The Effects of Mergers in Differentiated products Industries: Logit Demand and Structural Merger Policy," Papers 93-4, U.S. Department of Justice Antitrust Division, 1993.

\subsection{Links da Web}

VISUALIZING Multivariate Data. Disponível em:

http://www.mathworks.com/products/statistics/examples.html;jsessionid=8710ebe8da811cf15 681aff36bc8?file=/products/demos/shipping/stats/mvplotdemo.html\#2. Acesso em: $30 / 11 / 2013$

HALDRUP, N. Empirical analysis of price data in the deliniation of the relevant Market in competition analysis. Aarhus: Department of Economics. 2003. Disponível em:

http://papers.ssrn.com/sol3/papers.cfm?abstract_id=429120. Acesso em: 05/12/2011

PHILLIPS-Perron test. Disponível em:

http://en.wikipedia.org/wiki/Phillips\%E2\%80\%93Perron_test. Acesso em: 30/11/2013 


\section{Apêndice A}

Abaixo seguem os comandos de programação comentados, utilizados na definição da cointegração não linear proposto por (KAPETANIOS, 2006).






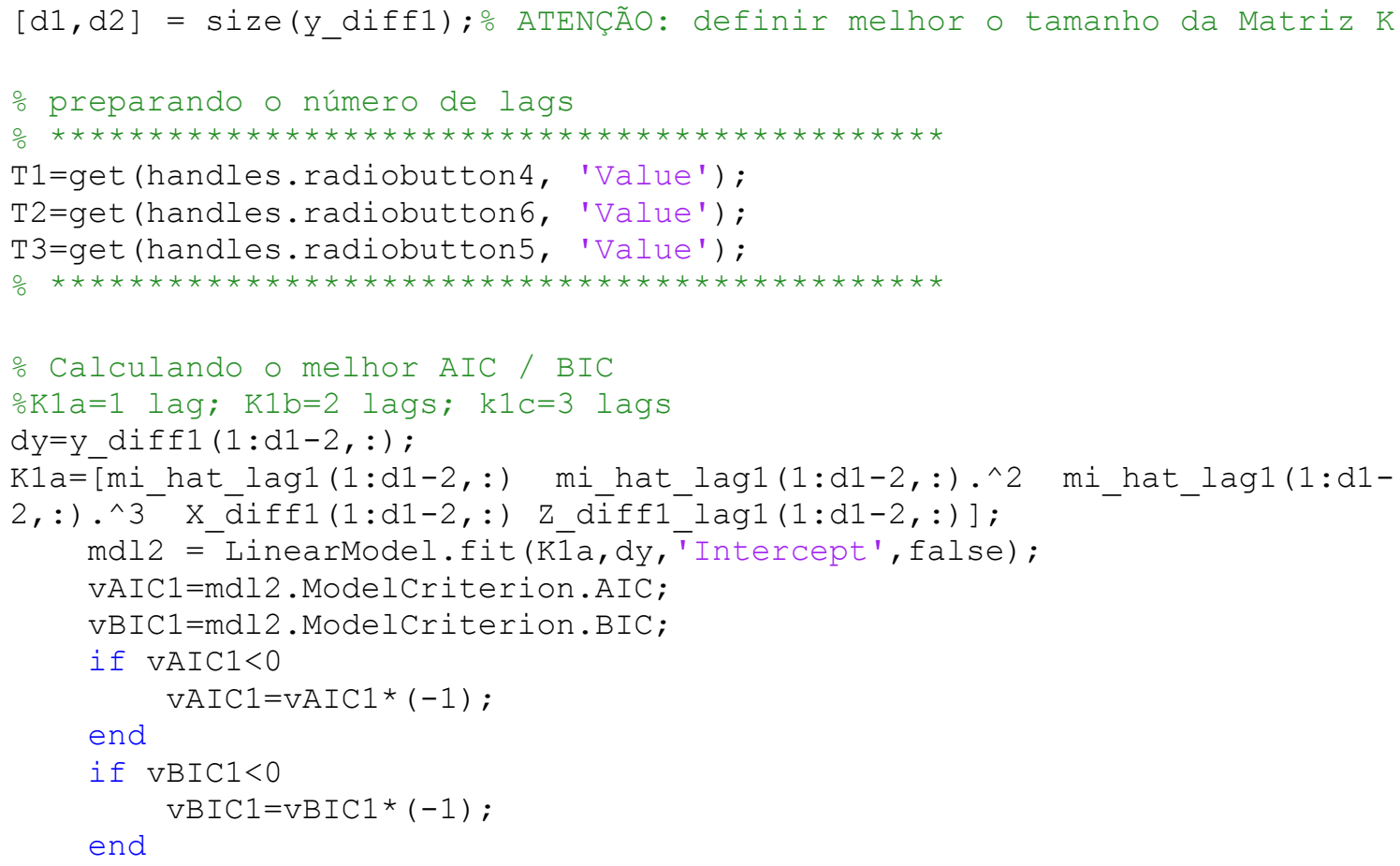

K1b $=\left[\mathrm{mi} h a t \_l a g 1(1: \mathrm{d} 1-2,:) \quad \mathrm{mi} h a t \_l a g 1(1: \mathrm{d} 1-2,:) \cdot \wedge 2\right.$ mi hat_lag1(1:d1-


mal2 = LinearModel.fit(K1b, dy, 'Intercept', false);

VAIC2=md12. ModelCriterion. AIC;

$\mathrm{VBIC} 2=\mathrm{mdl2}$. ModelCriterion.BIC;

if $\operatorname{VAIC} 2<0$ $\operatorname{vAIC} 2=\operatorname{vAIC} 2 *(-1)$;

end

if $\mathrm{VBIC} 2<0$

$\mathrm{vBIC} 2=\mathrm{vBIC} 2 *(-1) ;$

end

K1C $=\left[\mathrm{mi} h a t \_l a g 1(1: \mathrm{d} 1-2,:) \quad \mathrm{mi} h a t \_l a g 1(1: \mathrm{d} 1-2,:) \cdot{ }^{2} \mathrm{mi}\right.$ hat_lagl(1:d1-

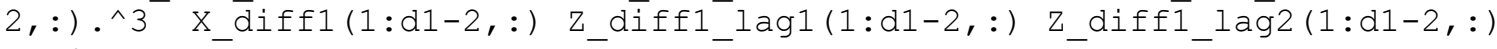
Z_diff1_laḡ3(1:d1-2,:)];



VAIC3=mdl2. ModelCriterion. AIC;

VBIC3=md12. ModelCriterion. BIC;

if $\operatorname{VAIC} 3<0$

$\operatorname{vAIC} 3=\operatorname{vAIC} 3 *(-1)$;

end

if $\mathrm{VBIC} 3<0$

$\operatorname{vBIC} 3=\operatorname{vBIC} 3 *(-1) ;$

end

\% Fator K são os regressores do deltay.

\% Executando conforme escolha de lag pelo usuário

if $\mathrm{T} 1==1 \quad \& \& \mathrm{~T} 2==0 \quad \& \& \mathrm{~T} 3==0$

$\mathrm{K} 1=\left[\mathrm{mi} h a t \_l a g 1(1: \mathrm{d} 1-2,:) \quad \mathrm{mi} h a t \_l a g 1(1: \mathrm{d} 1-2,:) . \wedge 2\right.$ mi_hat_lag1(1:d1-

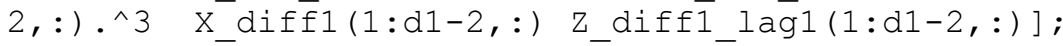

end

if $\mathrm{T} 1==0 \quad \& \& \mathrm{~T} 2==1 \quad \& \& \mathrm{~T} 3==0$

$\mathrm{K} 1=\left[\mathrm{mi}\right.$ hat_lag1 $(1: \mathrm{d} 1-2,:) \quad \mathrm{mi} h a t \_l a g 1\left(1: \mathrm{d} 1-2, \mathbf{:}^{\prime} .^{\wedge} 2\right.$ mi hat_lag1(1:d1-






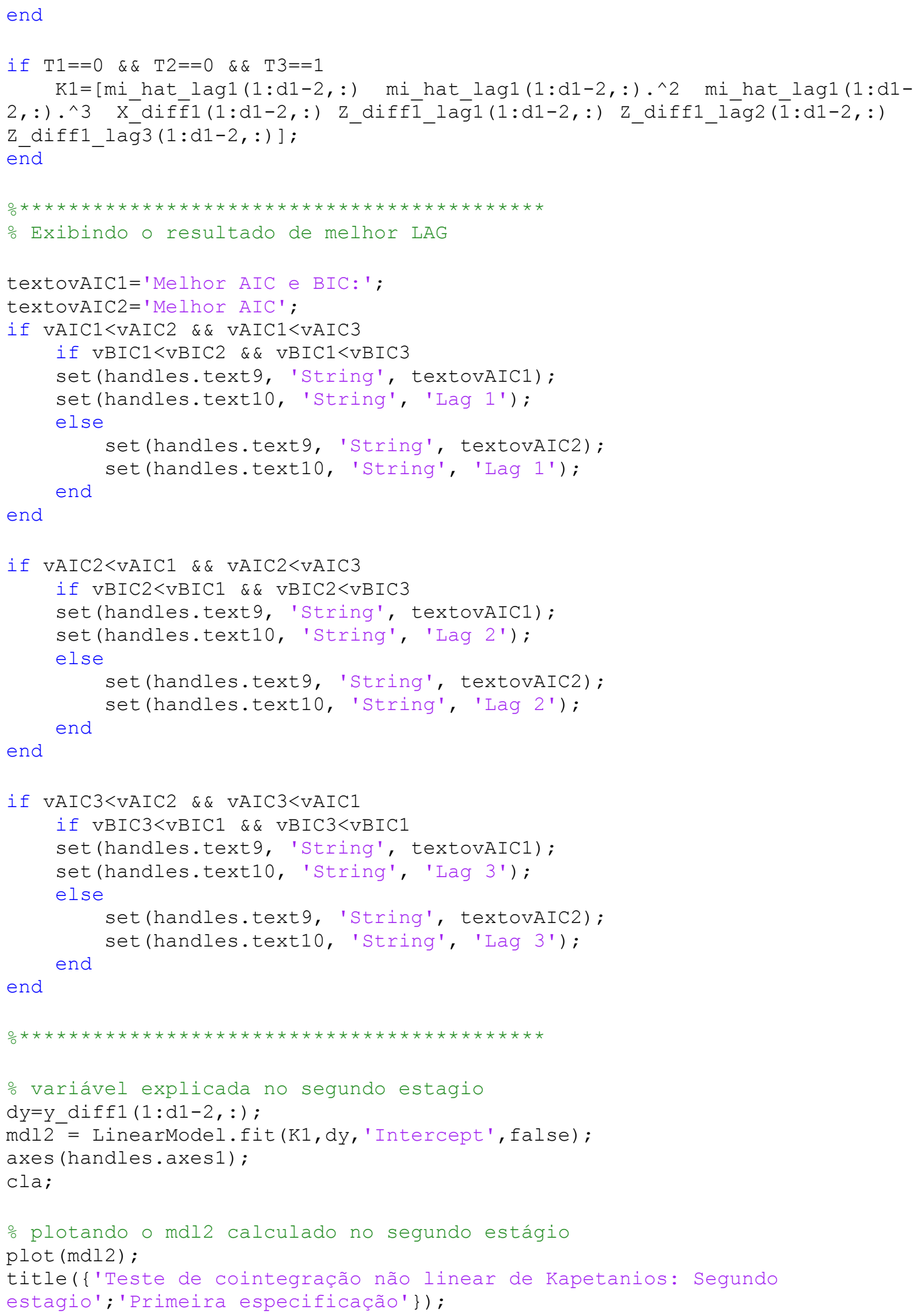




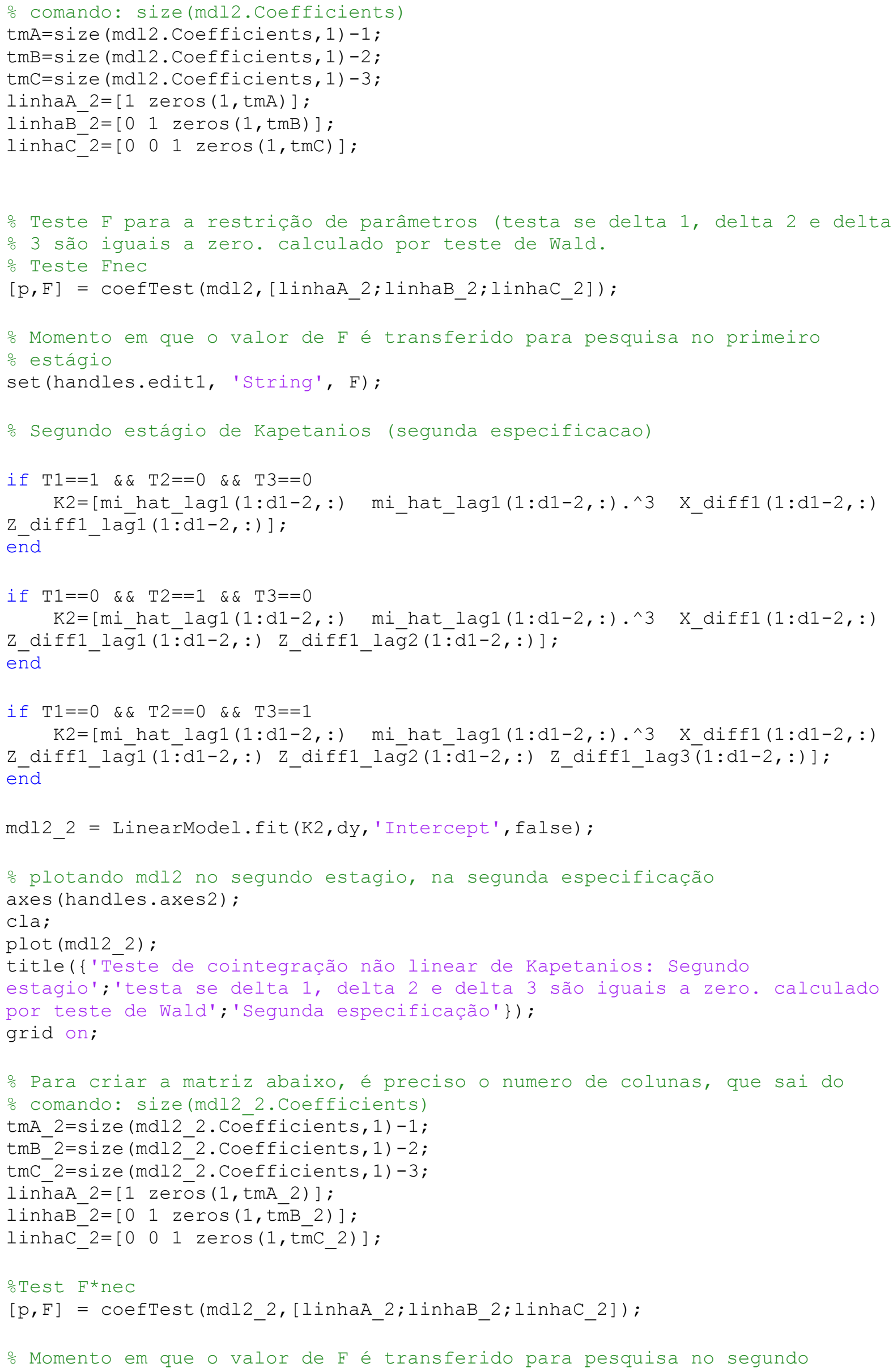




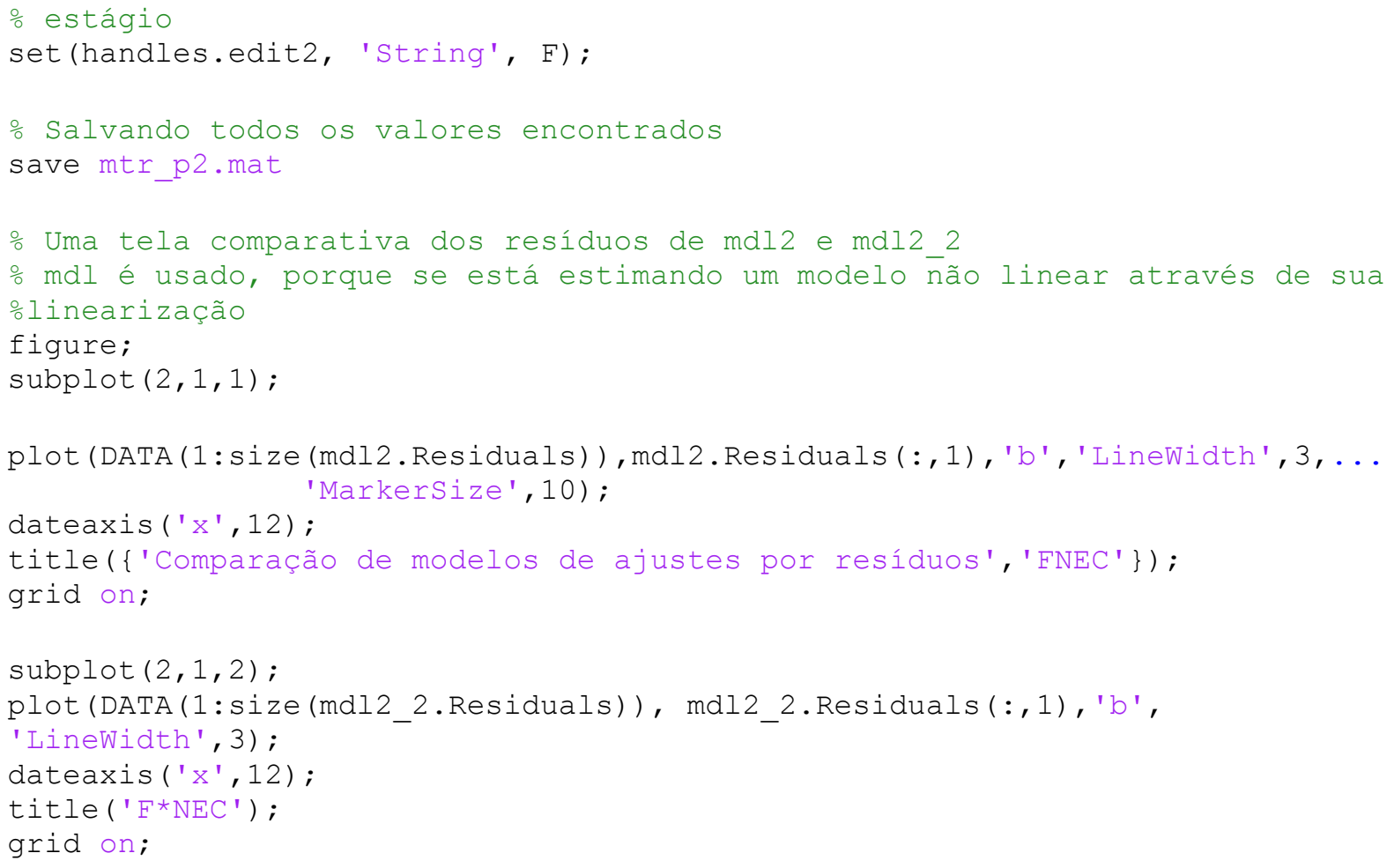




\section{Anexo A}

Conforme Nishijima (1998), o teste de Dickey-Fuller consiste em testar, para cada uma das séries, denominando $y_{\mathrm{t}}$ a variável sob análise, que compõem o VAR (Vetor AutoRegressivo) a ser estimado, o seguinte modelo autoregressivounivariado,

$$
\Delta y_{t}=\alpha+\mu . t+(\beta-1) y_{t-1}+\varepsilon_{t}, \varepsilon_{t} \sim N\left(0, \sigma_{\varepsilon}\right)
$$

Onde se testa a hipótese de $(\beta-1)$ ser igual à zero sob a hipótese nula, ou se ( $\beta-1)$ é um valor negativo, sob a hipótese alternativa ${ }^{i}$. Se a hipótese nula não puder ser rejeitada, então o processo de geração da variável é não estacionário, isto é, é integrado de primeira ordem. Nesta condição, sob $\mathrm{H}_{0}$, Dickey e Fuller (1979) mostra que os valores da distribuição de $(\beta-1)=\rho$ não têm distribuição limite normal padrão, bem como o das estatísticas de teste associadas a estes estimadores, que não tenderão para distribuição limite usuais, mas sim para uma soma de processos de Wiener, conforme a presença ou ausência de constante e/ou tendência no modelo.

Dickey e Fuller (1979) apresentam uma tabela com os valores críticos das estatísticas t associadas a $\rho$ - conforme o modelo escolhido para ser estimado, ver equações (i), (ii) e (iii) na tabela (2a) abaixo - obtidos a partir de experimentos de Monte Carlo, sob a hipótese nula de que o modelo gerador dos dados é um passeio aleatório sem drift. Assim, de acordo com o modelo adotado para estimação tem-se a estatística de teste específica associada à estimativa de $\rho$, sob a hipótese de que $\varepsilon_{t}$, os resíduos da equação, sejam gaussianos, identicamente e independentemente distribuídos (i.i.d.):

\section{TABELA 2a - modelos e estatísticas $t$ associadas a $\rho$}

\begin{tabular}{|l|l|}
\hline Modelo & estatística t associada a $\rho$ \\
\hline ( i ) $\Delta y_{t}=\rho y_{t-1}+\varepsilon_{t}$ & $\hat{\tau}$ \\
\hline ( ii ) $\Delta y_{t}=\alpha+\rho y_{t-1}+\varepsilon_{t}$ & $\hat{\tau}_{\mu}$ \\
\hline ( iii ) $\Delta y_{t}=\alpha+\mu t+\rho y_{t-1}+\varepsilon_{t}$ & $\hat{\tau}_{\tau}$ \\
\hline
\end{tabular}

Se os dados forem gerados por (i) e $\rho=0$, então $y_{t}$ constitui-se num passeio aleatório sem $d$ rift; se forem gerados por (ii) e $\rho=0$, então $y_{t}$ representa um passeio aleatório com 
drift; e, finalmente, se os dados forem gerados por (iii) e $\rho=0, y_{t}$ corresponde a um passeio aleatório em torno de uma tendência linear.

Dickey e Fuller (1981) também calculam valores críticos para testes de razão de verossimilhança de conjuntos de restrições: $\mu=\rho=0$, estatística $\phi_{3} ; \alpha=\mu=\rho=0$, estatística $\phi_{2}$; e $\alpha=\rho=0$, estatística $\phi_{1}$. Pois, dependendo do modelo que se estima e do verdadeiro modelo gerador, quase sempre desconhecido, tem-se variações nas distribuições limites de acordo com a presença ou ausência de tendência temporal $\mu$ e da constante $\alpha$.

O teste Dickey-Fuller Aumentado (ADF) é apresentado por estes mesmos autores (1981) como uma maneira de se evitar o problema de autocorrelação serial nos resíduos do modelo estimado, dado que na obtenção de estatísticas de teste DF éfundamental a hipótese de que os erros sejam i.i.d. e normais. A idéia é controlar a autocorrelação através da introdução de um número suficiente de defasagens da variável em diferença, $\Delta y_{t-i}, i=1$, 2...,n. As estatísticas de testes DF tabuladas para o modelo sem as defasagens não se alteram, podendo ser utilizadas sem problemas, uma vez que os parâmetros das defasagens não afetam a distribuição destas estatísticas.

O teste Phillips-Perron faz uma correção não paramétrica sobre o teste Dickey-Fuller para corrigir seu problema de endogeneidade.

Sob a hipótese nula, a variável é descrita por um processo de integração não estacionário, isto é, é usado uma análise das séries de tempo para testar a hipótese nula de que uma série de tempo é integrada de ordem 1. Baseado no teste de Dickey-Fuller da hipótese nula, para $\delta=0$ em $\Delta y_{t-1}+u_{t}$ em $\Delta y_{t}=\delta y_{t-1}+u_{t}$, onde $\Delta$ é o operador da primeira diferença. Assim como o teste de Dickey-Fuller aumentado, o teste de Phillips-Perron aborda a questão de que os dados de geração de processo para $y_{t}$ pode ter uma ordem superior de autocorrelação do que é admitido na equação de teste - tornando $y_{t-1}$ endógeno e invalidando, assim, o teste-t de Dickey-Fuller (PHILLIPS, 1988).

${ }^{\mathrm{i}}$ Exclui-se a possibilidade de valores positivos para não contemplar as raízes explosivas. 